Article

\title{
Development and Experimental Investigation of a Multistage Oxygen Compressor Unit with a Non-Crank Mechanism for the Onboard Oxygen Generating System
}

\author{
Yi Guo ${ }^{1}$, Yongfei Wang ${ }^{2, *}$, Shengdun Zhao ${ }^{2}$ and $\mathrm{Bo} \mathrm{Li}^{2}$ \\ 1 School of Energy and Power Engineering, Xi'an Jiaotong University, Xi'an 710049, China; \\ yiguo666@mail.xjtu.edu.cn \\ 2 School of Mechanical Engineering, Xi'an Jiaotong University, Xi'an 710049, China; \\ sdzhao@mail.xjtu.edu.cn (S.Z.); xjtulibo@stu.xjtu.edu.cn (B.L.) \\ * Correspondence: wangyongfei324@mail.xjtu.edu.cn; Tel.: +86-1348-812-6840
}

Received: 21 November 2019; Accepted: 20 December 2019; Published: 24 December 2019

check for updates

\begin{abstract}
The oxygen compressor is one of the key components in the onboard oxygen generating system (OBOGS), with a high-pressure canister for backup. In this paper, a multistage compressor unit with a non-crank mechanism is proposed for the compression of the generated oxygen for storage in the high-pressure canister in the oxygen backup line of the OBOGS. The working principle, control strategy, and the design method of the key components of the non-crank compressor are provided to realize the preliminary design. The experimental study was carried out to investigate the control accuracy and the technical feasibility, including the compression capacity and the cooling performance. Results show that the motion control program could realize the motion scheme of the compressor with an error of less than $2 \%$. The discharge pressure reached a relative stability after around 40 cycles of compression, while the discharge temperature achieved relative stability after approximately 100 cycles. The average discharge pressure at the last stage could meet the pressure requirement under standard working conditions. The average inlet temperature of the oxygen to the gasholder was $25^{\circ} \mathrm{C}$ under standard working conditions.
\end{abstract}

Keywords: oxygen compressor; servo motor; non-crank mechanism; system development; component design; experimental investigation

\section{Introduction}

The compressed liquid or gaseous oxygen in bottles has been the oxygen source for several decades when military aircraft operate at a high altitude where there is insufficient oxygen for human beings to maintain consciousness [1]. This has resulted in the development of the onboard oxygen generating system (OBOGS) since the early 1970s [2,3]. An OBOGS is a promising alternative to liquid oxygen in modern military aircraft for supporting the pilot during a long flight [4], which could guarantee safety, improve the mission efficiency, extend the flight duration, and significantly reduce the operational cost $[5,6]$. In OBOGS, the breathable gas is generally produced by concentrating the oxygen through a molecular sieve [7]. In the molecular sieve, the nitrogen molecules are filtered out by the zeolite when the air is passed through such that the oxygen is separated from the inert gases [8].

The effects of the sieve type on the oxygen generation concentration were investigated to improve the performance of OBOGS. Ghoreishi et al. [9] optimized the OBOGS with $13 \times$ zeolite in a commercial aircraft through a predictive dynamic model, where the coupled mass, energy, and momentum differential equations were solved using the implicit central finite-difference technique. Jiang et al. [10] 
experimentally investigated the water content in the bleed air and the product gas in an OBOGS with two different sieves (NaX type and LiX type) under different operating conditions. Ceramic membrane separation technology has also been considered for the oxygen generation by scholars. Jiang et al. [11] experimentally compared the oxygen generation performance between the electricity-driven and pressure-driven ceramic membrane separation oxygen generation methods for an OBOGS under different temperatures, pressures of the feed air, and flow rates of the produced oxygen gas.

Apart from the gas separation and concentration, the oxygen compressor is one of the key components in an OBOGS with a high-pressure canister for the oxygen backup [12,13]. According to the US Federal Aviation Administration, the oxygen is stored in high-pressure (12.4-15.2 MPa) containers. Furthermore, the average flow rate for the pilot ventilation specified by the American MIL-D-8683-D military standard is $13.35 \mathrm{~L} / \mathrm{min}$ [11]. Therefore, the design conditions of the compressor unit are set as $15 \mathrm{MPa}$ for the discharged pressure and $15 \mathrm{~L} / \mathrm{min}$ for the flow rate. The inlet pressure for the design was set to $0.2 \mathrm{MPa}$ based on the literature [10], while the inlet temperature was $38^{\circ} \mathrm{C}$ based on the data from the literature [14]. Therefore, the reciprocating compressor was chosen as the compressor type for the design in this study as it is easily implementable for the reciprocating piston compressor to achieve the desired combination of flow and pressure ratio by varying the configurations of stages and trains [15].

Reciprocating compressors are applied and investigated in various areas due to several advantages, such as their simple design, easy installation, and low initial cost. The control strategy has been investigated by researchers for the operation optimization of the reciprocating compressor. Aprea et al. [16] identified the optimal current efficiency for both the reciprocating and scroll compressor for the variable speed compressors in order to obtain the control algorithm for the optimization of the variable speed compressor in terms of energy, exergy, and economy aspects. The stepless capacity control system has been studied for the reciprocating compressors by several scholars [17-20]. It was found by Wang et al. [17] that the valve clearance Mach number had a negative influence on the thermal performance, while the optimal valve displacement was suggested by Bin et al. [18]. Energy consumption could be saved through the proposed rotary control valve [19] or adjusting the opening of the suction valve [20].

Mathematical models and simulations have been studied for predicting the thermodynamic cycle in order to reduce energy consumption and improve compressor efficiency [21,22]. Negrão et al. [23] presented a semi-empirical model to predict the unsteady behavior of the reciprocating compressor in a transient regime based on thermodynamic equations fitted to the manufacturer data of two reciprocating compressors. The proposed model was validated by the start-up and cycling experiments, which showed a good agreement in the mass flow rate and power consumption. Diniz et al. [24] proposed an advanced simulation model for the reciprocating compressor of a household refrigerator to predict the on-off cycling transients and the inside heat and fluid flow dynamics. Simulations showed that actual system conditions need to be considered in the selection of the compressor for the household refrigerator to save on energy consumption.

However, to the best of the authors' knowledge, an investigation on the compressor for the oxygen backup in OBOGS has not been reported. Furthermore, the conventional reciprocating compressor is driven by the induction motor through the crank mechanism. This crank structure would significantly reduce the mechanical efficiency $[25,26]$. Therefore, the aims of this work were: (I) to propose a compressor unit with the servo motor and ball screw unit that replace the conventional crank mechanism for OBOGS; (II) to provide the design method for key components and the control strategy for this non-crank compressor unit; and (III) to experimentally investigate the control accuracy, compression capacity, and cooling performance of the proposed compressor unit.

\section{System Design and Working Principle}

As shown in Figure 1, the non-crank compressor unit developed in this study mainly consisted of the servo motor, planetary reducer, ball screw pair, cylinder assemblies, and the heat exchanger. 


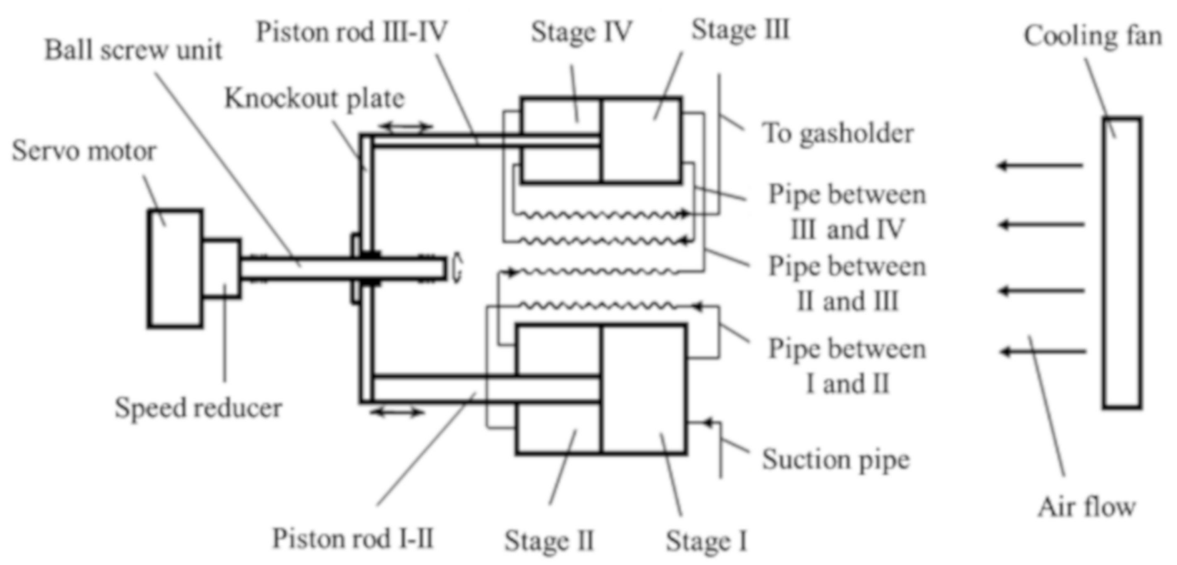

(a)

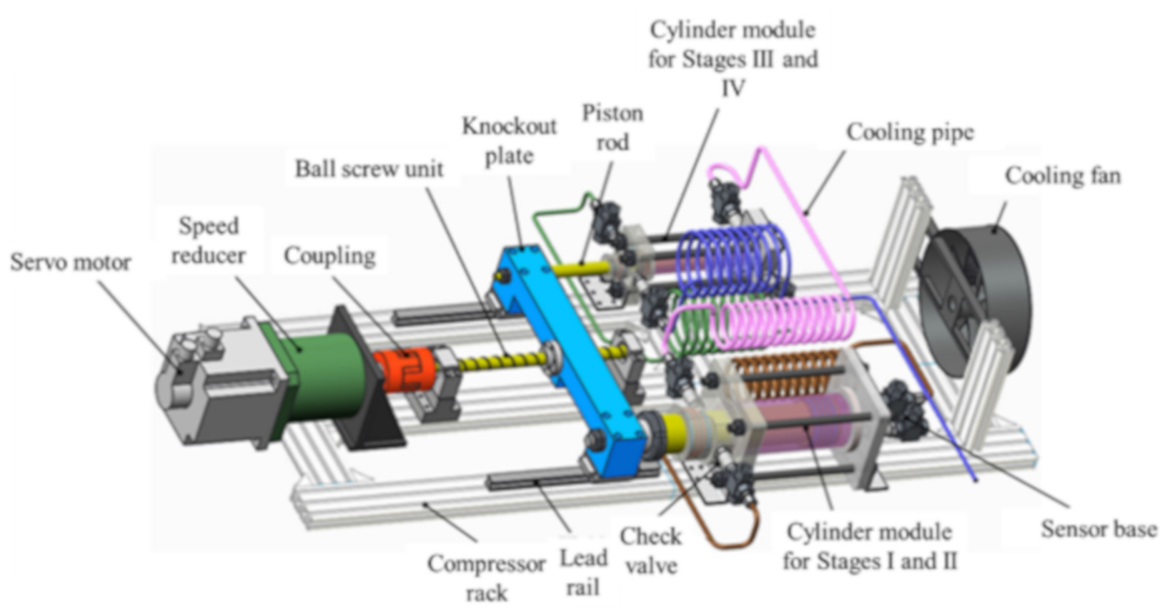

(b)

Figure 1. (a) Structural diagram and (b) 3D model of the multistage compressor unit.

The servo motor was applied in the compressor system in order to meet different requirements of the flow rate by adjusting the motor speed. The planetary reducer was installed in the system to reduce the speed but increase the rotational torque due to the small flow rate of the compressor, which decreases the installed power of the motor. The force from the motor is transferred to the knockout plate through the ball screw pair. The different moving directions of the knockout plate are achieved by the positive inversion of the servo motor. The pressure of the oxygen is then increased by the movement of the piston, which is driven by the knockout plate that is rigidly connected with the piston rod. Through this design, the non-crank compressor driven by the servo motor has a simpler structure compared to the traditional electric drive compressor, which contains more components, such as the crankshaft, connecting rod, and the crank block. This consequently helps to avoid the piston wear due to the lateral force and potentially increase the mechanical efficiency.

The multistage compressor unit consists of two differential cylinders, each of which contains a rod cavity and a head port. All the rod cavities and head ports are working chambers for the compression process; therefore, this compressor unit is a four-stage unit. The cooling components in this unit contain the cooling fan and the spiral cooling pipes, where the cooling fan is used for the forced convective heat transfer, while the spiral cooling pipes were installed for the internal cooling between stages.

As shown in Figure 1, when the motor rotates forward, the piston rod moves toward the fan side due to the force of the knockout plate. The volume of the oxygen in stages I and III are then reduced while the pressure of the oxygen is increased. When the pressure of the oxygen exceeds the discharge pressure, the gas in stages I and III moves into the pipe between stages I and II and the pipe between 
stages III and IV, respectively. During this process, the volume in stages II and IV increases, which drives the suction of the gas from each respective prior stage.

In contrast, when the motor rotates backward, the piston rod moves toward the motor side when forced by the knockout plate, which consequently reduces the volume in stages II and IV and increases the pressure of the gas inside. When the pressure is above the discharge value, the gas in stages II and IV is discharged into the pipe between stages II and III and the pipe to the gasholder, respectively. Meanwhile, the oxygen is inhaled to stages I and III through the suction pipe and the pipe between stages II and III, respectively.

A comparison between the proposed compressor and the conventional compressor is presented in Figure 2. It is shown that the crankshaft, connecting rod, crosshead, and the balancing chamber are the necessary components in the conventional compressor, which are not required for the proposed compressor. The ball screw unit and the knockout plate are the basic components in the proposed compressor, which are unnecessary for the conventional compressor. In total, the proposed compressor has five fewer components compared to the conventional compressor.

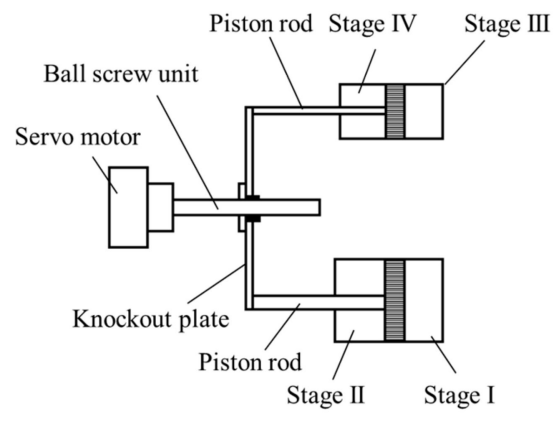

(a)

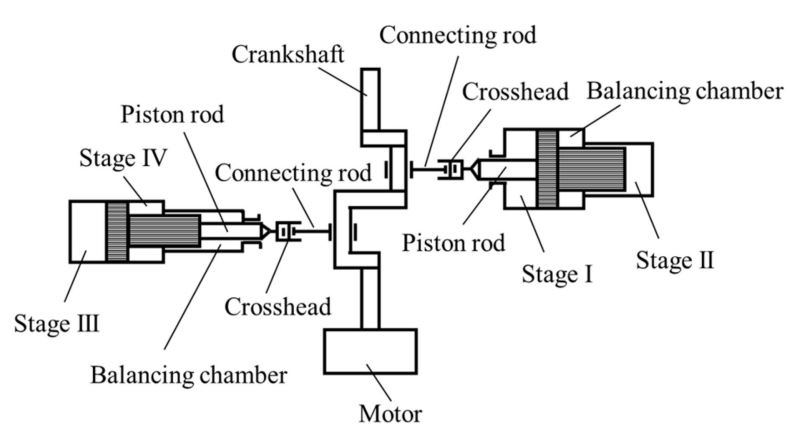

(b)

Figure 2. Structure comparison between (a) the proposed compressor and (b) the conventional compressor.

\section{Mathematical Modelling and Component Design}

As mentioned in Section 1, the requirements of the discharge pressure of the compressor unit are $15 \mathrm{MPa}$ under the design conditions of $15 \mathrm{~L} / \mathrm{min}$ for the flow rate, $0.2 \mathrm{MPa}$ for the inlet pressure, and $38^{\circ} \mathrm{C}$ for the inlet temperature.

\subsection{Mathematical Model for the Cylinder Design}

The pressure ratios of all stages are designed to be the same due to the low flow rate, which can be calculated using Equation (1):

$$
\varepsilon=\sqrt[4]{\frac{P_{d 4}}{P_{s 1}}}
$$

where $P_{d 4}$ is the discharge pressure in stage IV and $P_{s 1}$ is the suction pressure in stage I.

The gas pressure during the compression and expansion processes can be calculated using Equation (2) or Equation (3) [27]:

$$
\begin{aligned}
P V^{n_{V}} & =\text { constant } \\
\frac{P^{\frac{n_{T}-1}{n_{T}}}}{T} & =\text { constant }
\end{aligned}
$$

where $P$ is the pressure, $V$ is the specific volume, $n_{V}$ is the isentropic volume exponent, and $n_{T}$ is the isentropic temperature exponent.

For a real gas, the isentropic process can be obtained using Equations (4) and (5) [27]:

$$
\frac{\rho_{d}}{\rho_{s}}=\frac{Z_{s}}{Z_{d}} \frac{P_{d}}{P_{s}} \frac{T_{s}}{T_{d}}=\left(\frac{P_{d}}{P_{s}}\right)^{1 / n_{V}}
$$




$$
\frac{T_{s}}{T_{d}}=\left(\frac{P_{s}}{P_{d}}\right)^{n_{T}-1 / n_{T}}
$$

where $\rho$ is the density of the gas, $T$ is the temperature of the gas, $Z$ is the compressibility value, $s$ indicates the suction value, and $d$ indicates the discharge value.

More details for the calculation of the thermodynamic properties can be found in the literature [27]. Based on the thermodynamic properties, the stroke volume of stage $k$ is calculated using Equations (6) and (7):

$$
\begin{gathered}
V_{S K k}=q_{v} \frac{P_{s 1}}{P_{s k}} \frac{Z_{s k}}{Z_{s 1}} \frac{T_{s k}}{T_{S 1}} \frac{1}{\lambda_{v k} \lambda_{p k} \lambda_{T k} \lambda_{l k}} \frac{1}{N} \\
\lambda_{v k}=1-\alpha_{k}\left(\frac{Z_{s k}}{Z_{s d}} \varepsilon^{\frac{1}{n_{T}}}-1\right)
\end{gathered}
$$

where $q_{v}$ is the volumetric flow rate, $V_{S K}$ is the stroke volume, $N$ is the rotational speed, $\alpha$ is the relative clearance volume, $\lambda_{v}$ is the volume coefficient, $\lambda_{p}$ is the pressure coefficient, $\lambda_{T}$ is the temperature coefficient, and $\lambda_{l}$ is the leakage coefficient.

The diameter of the cylinder of stages I and III can then obtained based on Equation (8), while that of stages II and IV can be obtained based on Equation (9):

$$
\begin{gathered}
V_{S K}=\frac{1}{4} \pi D^{2} S \\
V_{S K}=\frac{1}{4} \pi\left(D^{2}-d^{2}\right) S
\end{gathered}
$$

where $D$ is the diameter of the cylinder, $d$ is the diameter of the piston rod, and $S$ is the piston stroke.

\subsection{Load Calculation and the Selection of the Ball Screw Pair}

The displacement and velocity of the piston at time $t$ can be calculated using Equations (10) and (11), respectively:

$$
\begin{gathered}
x=\frac{S}{2}-\frac{S}{2} \cos \left(\frac{2 \pi}{t_{c}} t\right) \\
v=\frac{S \pi}{t_{c}} \sin \left(\frac{2 \pi}{t_{c}} t\right)
\end{gathered}
$$

where $x$ is the displacement of the piston, $v$ is the velocity of the piston, and $t_{c}$ is the time of one compression cycle.

The rotational speeds of the ball screw and the servo motor can be calculated using Equations (12) and (13), respectively:

$$
\begin{aligned}
N_{B S} & =\frac{60 v}{P_{h}} \\
v N_{S M} & =\frac{60 v}{P_{h}} I
\end{aligned}
$$

where $N_{B S}$ is the rotational speed of the ball screw, $N_{S M}$ is the rotational speed of the servo motor, $P_{h}$ is the screw lead of the ball screw pair, and $I$ is the reduced ratio of the speed reducer.

The volume of the cylinder at time $t$ can be calculated using Equation (14):

$$
V_{t}=V_{S K}\left(\frac{P_{S}}{P_{t}}\right)^{\frac{1}{1.4}}
$$

where $V_{t}$ and $P_{t}$ are the volume and pressure at time $t$, respectively. 
Therefore, when the pressure is increased to the discharge value, the volume can be calculated using Equation (15):

$$
V_{t}=V_{S K}\left(\frac{P_{s}}{P_{d}}\right)^{\frac{1}{1.4}}
$$

The discharge time $t_{d}$ can then be obtained by combining Equations (10) and (15). The pressure before the discharge time can be calculated using Equation (16) through substituting Equation (10) into Equation (14):

$$
P_{t}=P_{s}\left[\frac{S+\delta}{\frac{S}{2}+\delta+\frac{S}{2} \cos \left(\frac{2 \pi}{t_{c}} t\right)}\right]^{1.4}
$$

where $\delta$ is the length of the clearance volume.

The load on the ball screw can be calculated using Equation (17):

$$
\begin{aligned}
& F_{B S}= \begin{cases}F_{G 1}+F_{G 4}-F_{G 1} & 0<t \leq t_{d} \\
F_{G 2}+F_{G 4}-F_{G 1}-F_{G 3} & t_{d}<t \leq \frac{t_{c}}{2} \\
-\left(F_{G 1}+F_{G 3}\right) & \frac{t_{c}}{2}<t \leq \frac{t_{c}}{2}+t_{d} \\
-\left(F_{G 1}+F_{G 3}-F_{G 2}-F_{G 4}\right) & \frac{t_{c}}{2}+t_{d}<t \leq t_{c}\end{cases} \\
& = \begin{cases}P_{s 2}^{\prime}\left[\frac{S+\delta}{\frac{S}{2}+\delta+\frac{S}{2} \cos \left(\frac{2 \pi}{t_{c}} t\right)}\right]^{1.4} A_{2}+P_{s 4}^{\prime}\left[\frac{S+\delta}{\frac{S}{2}+\delta+\frac{S}{2} \cos \left(\frac{2 \pi}{t_{c}} t\right)}\right]^{1.4} A_{4}-P_{s 1}^{\prime} A_{1} & 0<t \leq t_{d} \\
P_{d 2}^{\prime} A_{2}+P_{d 4}^{\prime} A_{4}-P_{s 1}^{\prime} A_{1}-P_{s 3}^{\prime} A_{3} & t_{d}<t \leq \frac{t_{c}}{2} \\
-\left\{\left(P_{s 1}^{\prime} A_{1}+P_{s 3}^{\prime} A_{3}\right)\left[\frac{S+\delta}{\frac{S}{2}+\delta+\frac{S}{2} \cos \left(\frac{2 \pi}{t_{c}} t\right)}\right]^{1.4}\right\} & \frac{t_{c}}{2}<t \leq \frac{t_{c}}{2}+t_{d} \\
-\left(P_{d 1}^{\prime} A_{1}+P_{d 3}^{\prime} A_{3}-P_{s 2}^{\prime} A_{2}-P_{s 4}^{\prime} A_{4}\right) & \frac{t_{c}}{2}+t_{d}<t \leq t_{c}\end{cases}
\end{aligned}
$$

where $F_{B S}$ is the load on the ball screw; $F_{G}$ is the gas force; $P_{s}^{\prime}$ is the actual suction pressure; $P_{d}^{\prime}$ is the actual discharge pressure; $A$ is the area of the piston; - indicates the compressive stress; and 1, 2, 3, and 4 indicate stages I, II, III, and IV, respectively.

The model of the ball screw pair can then be selected based on the maximum value of the load calculated using Equation (17).

\subsection{Torque Calculation and the Selection of the Servo Motor}

The torque and angular acceleration of the servo motor can be calculated using Equations (18) and (19), respectively:

$$
\begin{gathered}
T_{S M}=F_{B S} \frac{P_{h}}{2 \pi \eta} I \\
a_{S M}=\frac{d \omega}{d t}=\frac{d\left(2 \pi \frac{N_{S M}}{60}\right)}{d t}=\frac{d\left(\frac{2 \pi^{2} I S \sin \left(\frac{2 \pi}{t_{c}} t\right)}{P_{h} t_{c}}\right)}{d t}=\frac{4 \pi^{3} I S}{P_{h} t_{c}^{2}} \cos \left(\frac{2 \pi}{t_{c}} t\right)
\end{gathered}
$$

where $T_{S M}$ is the torque of the servo motor, $a_{S M}$ is the angular acceleration of the servo motor, and $\eta$ is the transmission efficiency of the ball screw pair, which was set to 0.9 in the design.

The equivalent rotating inertia of the servo motor can be calculated using Equation (20):

$$
J_{S M}^{\prime}=m\left(\frac{P_{h}}{2 \pi}\right)^{2}\left(\frac{1}{I}\right)^{2}+J_{B S}\left(\frac{1}{I}\right)^{2}+J_{S R}+J_{S M}
$$

where $m$ is the mass of the moving component; $J_{S M}^{\prime}$ is the equivalent rotating inertia of the servo motor; $J_{B S}$ is the rotating inertia of the ball screw; and $J_{S R}$ and $J_{S M}$ are the rotating inertias of the speed reducer and the servo motor, respectively. 
The total torque of the servo motor can be calculated using Equation (21):

$$
T_{S M, t}=T_{S M}+J_{S M}^{\prime} a_{S M}=F_{B S} \frac{P_{h}}{2 \pi \eta} I+J_{S M}^{\prime} a_{S M}
$$

The selection of the servo motor can then be achieved according to the total torque and rotational speed calculated.

\subsection{Sizing of the Wall Thickness of Cylinders}

The wall thickness of the cylinder $h$ can be calculated using Equations (22) and (23):

$$
\begin{aligned}
& h=\frac{P_{d}^{\prime} D}{2\left[\sigma_{b}\right]} \\
& {\left[\sigma_{b}\right]=\frac{\sigma_{s}}{n}}
\end{aligned}
$$

where $\left[\sigma_{b}\right]$ is the allowable stress; $\sigma_{s}$ is the yield strength; and $n$ is the safety factor, which was set to 3 in this study.

The cylinder works under the gas pressure and the preload on the end cover. The maximum radial and tangential stresses due to the gas pressure can be calculated using Equations (24) and (25), respectively:

$$
\begin{gathered}
\sigma_{\text {rmax }}=-P_{d}^{\prime} \\
\sigma_{\text {tmax }}=P_{d}^{\prime} \frac{r_{2}^{2}+r_{1}^{2}}{r_{2}^{2}-r_{1}^{2}}
\end{gathered}
$$

where $\sigma_{\text {rmax }}$ is the maximum radial stress, $\sigma_{\text {tmax }}$ is the maximum tangential stress, $r_{1}$ is the inner radius of the cylinder, and $r_{2}$ is the external radius of the cylinder.

The maximum axial stress due to the preload can be calculated using Equations (26) and (27):

$$
\begin{gathered}
F_{a}=F^{\prime \prime}+F_{G}=F^{\prime \prime}+P_{d}^{\prime} \pi r_{1}^{2} \\
\sigma_{\text {amax }}=\frac{F_{a}}{\pi\left(r_{2}^{2}-r_{1}^{2}\right)}
\end{gathered}
$$

where $F_{a}$ is the force due to the preload; $F_{G}$ is the gas force; $F^{\prime \prime}$ is the residual force from the bolts, which was set to $1.5 F_{G}$; and $\sigma_{a \max }$ is the maximum axial stress due to the preload.

The combined stress of the cylinder can then be calculated using Equation (28):

$$
\sigma_{c}=\sqrt{\frac{1}{2}\left[\left(\sigma_{t \max }-\sigma_{r \max }\right)^{2}+\left(\sigma_{r \max }-\sigma_{a \max }\right)^{2}+\left(\sigma_{a \max }-\sigma_{\text {tmax }}\right)^{2}\right]}
$$

\subsection{Design of the Spiral Cooling Pipe}

The structure and major parameters of the spiral cooling pipe are shown in Figure 3.

The heat transfer rate of the oxygen through the spiral cooling pipe can be calculated using Equation (29):

$$
Q=q_{m} \overline{C_{p}}\left(T_{d}^{\prime}-T_{s}\right)
$$

where $Q$ is the heat transfer rate, $q_{m}$ is the mass flow rate, and $\overline{C_{p}}$ is the average specific heat capacity.

The inner heat transfer coefficient can be calculated using Equations (30)-(33) [28]:

$$
\overline{h_{i}}=\frac{\frac{0.44994 \times 10^{-3} \bar{T}^{0.7456}}{1+56.699 / \bar{T}}}{D_{i}} \overline{\operatorname{Re}}^{0.8} \overline{\operatorname{Pr}}^{0.3}
$$




$$
\begin{gathered}
\overline{R e}=\frac{\overline{\rho v_{g}} D_{i}}{\bar{\mu}} \\
\overline{\operatorname{Pr}}=\frac{\overline{\mu c_{p}}}{\overline{\lambda_{s}}} \\
\overline{v_{g}}=\frac{S}{t_{c} / 2} \frac{D^{2}-d^{2}}{D_{i}^{2}}
\end{gathered}
$$

where $\overline{h_{i}}$ is the average inner heat transfer coefficient, $\overline{v_{g}}$ is the average velocity of the oxygen gas inside the spiral cooling pipe, $\bar{\rho}$ is the average density of the oxygen gas, $\bar{\mu}$ is the average dynamic viscosity of the oxygen gas, $\overline{\lambda_{s}}$ is the average thermal conductivity of the oxygen gas, and $D_{i}$ is the inner diameter of the spiral cooling pipe.

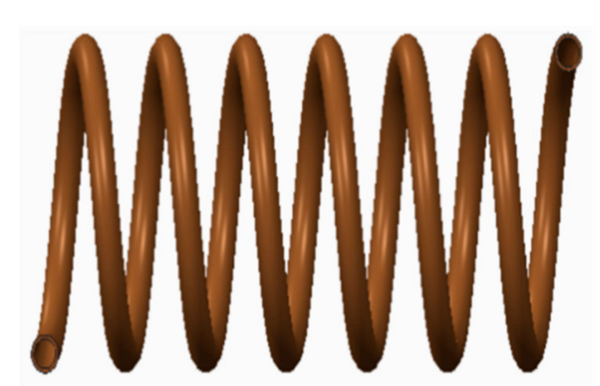

(a)

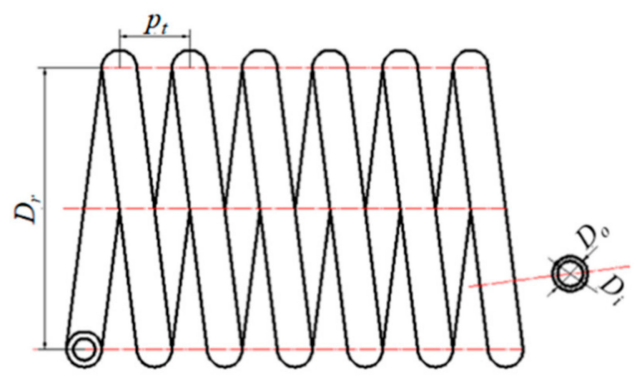

(b)

Figure 3. Structure of the spiral cooling pipe. (a) 3D schematic; (b) Dimension explanation.

The external heat transfer coefficient and be calculated using Equations (34) and (35) [28]:

$$
\begin{aligned}
\overline{h_{o}}=0.683 \frac{\lambda_{\text {air }}}{D_{o}} \operatorname{Re}^{0.466} \operatorname{Pr}^{1 / 3} & =0.683 \frac{\lambda_{\text {air }}}{D_{o}}\left(\frac{u D_{o}}{\vartheta}\right)^{0.466}\left(\frac{\mu_{\text {air }} c_{\text {air }}}{\lambda_{\text {air }}}\right)^{1 / 3} \\
u & =\frac{q_{C F}}{A_{C F}}
\end{aligned}
$$

where $\overline{h_{0}}$ is the average external heat transfer coefficient, $\lambda_{\text {air }}$ is the heat conductivity of the air, $u$ is the velocity of the air, $\mu_{\text {air }}$ is the dynamic viscosity of the air, $c_{a i r}$ is the specific heat capacity of the air, $\vartheta$ is the kinematic viscosity of the air, $D_{o}$ is the external diameter of the spiral cooling pipe, $q_{C F}$ is the maximum flow rate of the cooling fan, and $A_{C F}$ is the air supply area of the cooling fan.

The heat transfer coefficient outside the spiral cooling pipe can be calculated using Equation (36):

$$
U_{o}=\frac{1}{\frac{1}{\overline{h_{i}}} \frac{D_{o}}{D_{i}}+\frac{D_{o}}{2 \lambda_{p}} \ln \frac{D_{o}}{D_{i}}+\frac{1}{\overline{h_{o}}}}
$$

where $U_{o}$ is the heat transfer coefficient outside the spiral cooling pipe, and $\lambda_{p}$ is the heat conductivity of the spiral cooling pipe.

The heat exchange of the oxygen gas in the spiral cooling pipe between stages I and II and stages II and III is a downstream heat transfer, while that of the pipe between stages III and IV and stage IV and the gasholder is a counter-flow heat transfer. The temperature differences of the heat exchange in the downstream pipe $\Delta \mathrm{T}_{D S}$ and the counter-flow pipe $\Delta \mathrm{T}_{C F}$ can be calculated using Equations (37) and (38), respectively.

$$
\Delta \mathrm{T}_{D S}=\frac{\left(T_{d}^{\prime}-T_{C A, 1}\right)-\left(T_{s}-T_{C A, 2}\right)}{\ln \frac{T_{d}^{\prime}-T_{C A, 1}}{T_{s}-T_{C A, 2}}}
$$




$$
\Delta \mathrm{T}_{C F}=\frac{\left(T_{d}^{\prime}-T_{C A, 2}\right)-\left(T_{s}-T_{C A, 1}\right)}{\ln \frac{T_{d}^{\prime}-T_{C A, 2}}{T_{s}-T_{C A, 1}}}
$$

where $T_{C A, 1}$ and $T_{C A, 2}$ are the air temperatures before and after the spiral cooling pipe, respectively.

The horizontal length of the spiral cooling pipe in the downstream $L_{D S}$ and counter-flow pipe $L_{C F}$ can then be calculated using Equations (39) and (40), respectively:

$$
\begin{aligned}
& L_{D S}=\frac{Q /\left(U_{o} \Delta \mathrm{T}_{D S}\right)}{\pi D_{o}}=\frac{Q}{\pi D_{o} U_{o} \Delta \mathrm{T}_{D S}} \\
& L_{C F}=\frac{Q /\left(U_{o} \Delta \mathrm{T}_{C F}\right)}{\pi D_{o}}=\frac{Q}{\pi D_{o} U_{o} \Delta \mathrm{T}_{C F}}
\end{aligned}
$$

The actual length of the pipe $L_{P}$ in the spiral cooling pipe can be calculated using Equation (41):

$$
L_{P}=\frac{L_{x}}{P_{t}} \sqrt{\left(\pi D_{r}\right)^{2}+P_{t}^{2}}
$$

where $D_{r}$ is the diameter of the pipe cylinder, $P_{t}$ is the pitch, and $x$ can be $D S$ or $C F$.

Based on the geometry parameters determined through the method mentioned above, the cooling process in the spiral cooling pipe was analyzed using FLUENT software (ANSYS workbench 12.0, Ansys Inc., Canonsburg, PA, USA). The analysis process for the spiral pipe between stages I and II is presented as an example. The 3D model and the mesh of the heat transfer analysis are shown in Figure 4. The mesh was generated based on the full-hexahedral grid. Based on the grid dependence calculation results presented in Table 1, simulations were performed using the mesh with 354,744 grids. $\mathrm{Cu}$ was chosen as the material of the pipe in the analysis. Boundary conditions for the CFD analysis are presented in Table 2. The inlet boundary condition was set to be $12.8 \mathrm{~m} / \mathrm{s}$, as calculated using Equation (10). The discharge temperature from stage I was chosen as the inlet temperature as the boundary condition, while the outlet was set as the pressure-outlet. The pipe wall was set as the wall in the analysis with a thickness of $1 \mathrm{~mm}$ and the convection heat exchange by the flow temperature was set to $25^{\circ} \mathrm{C}$.

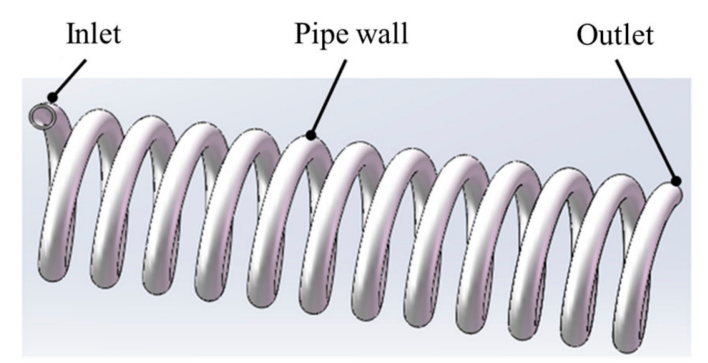

(a)

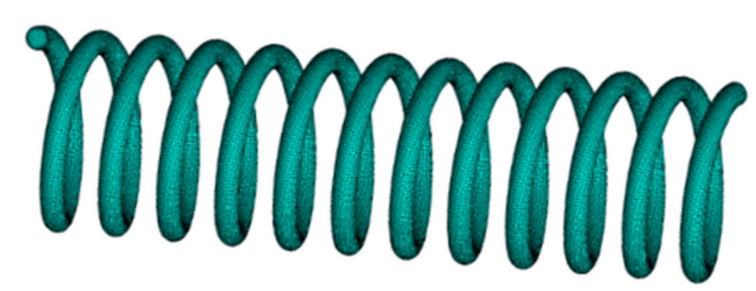

(b)

Figure 4. (a) 3D model and (b) mesh of the heat transfer analysis for pipe I-II.

Table 1. Grid independence calculation for the spiral cooling pipe.

\begin{tabular}{ccc}
\hline \multirow{2}{*}{ Mesh Number } & \multicolumn{2}{c}{ Outlet Temperature } \\
\cline { 2 - 3 } & Value $\left({ }^{\circ} \mathbf{C}\right)$ & Relative Error $(\mathbf{\%})$ \\
\hline 241,864 & 29.85 & 8.74 \\
308,442 & 31.43 & 3.28 \\
354,744 & 32.10 & 1.12 \\
418,965 & 32.46 & $/$ \\
\hline
\end{tabular}


Table 2. Boundary conditions for the CFD analysis.

\begin{tabular}{cc}
\hline Item & Information \\
\hline Velocity-inlet & $12.8 \mathrm{~m} / \mathrm{s} ; 165^{\circ} \mathrm{C}$ \\
Pressure-outlet & Default \\
Convective heat transfer coefficient & $45.8 \mathrm{~W} /\left(\mathrm{m}^{2} \cdot \mathrm{K}\right)$ \\
Free flow temperature $T$ & $25^{\circ} \mathrm{C}$ \\
\hline
\end{tabular}

\subsection{Stress Analysis of Key Components}

The stress analysis of the end cover and the knockout plate were carried out using ANSYS software (ANSYS workbench 12.0, Ansys Inc., Canonsburg, PA, USA) for the design purpose. There are four end covers for the cylinders in the compressor unit, which are for stages I, II, III, and IV, respectively. The structures of the end covers for all four stages in the stress analysis are shown in Figure 5. The shapes and the force conditions of the end cover for stages I, II, and III are similar to each other, while the end cover of stage IV is different in the design. Therefore, the end cover of stages II and IV were taken as examples for the expression of the stress analysis.

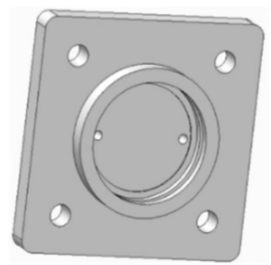

Stage I

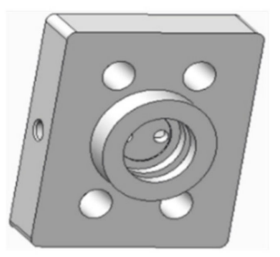

Stage III

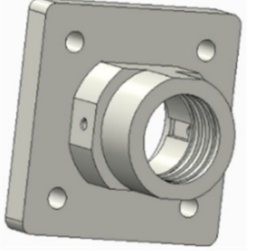

Stage II

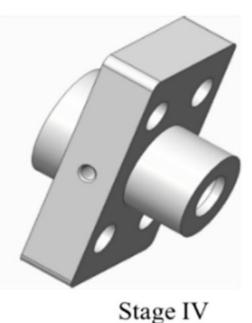

Figure 5. 3D model of the stress analysis for the cylinder.

As shown in Figure 6, the internal surface and the inner end face of the end cover were set fixed as the boundary condition as it was tight-fitted with the cylinder. The bolt hole was set with the preload of the screw force as the boundary condition, while all the faces the oxygen contacted were set with the gas pressure as the boundary condition.

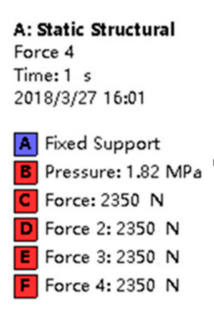

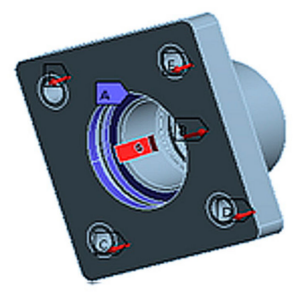

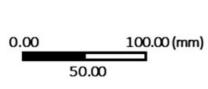

Stage II

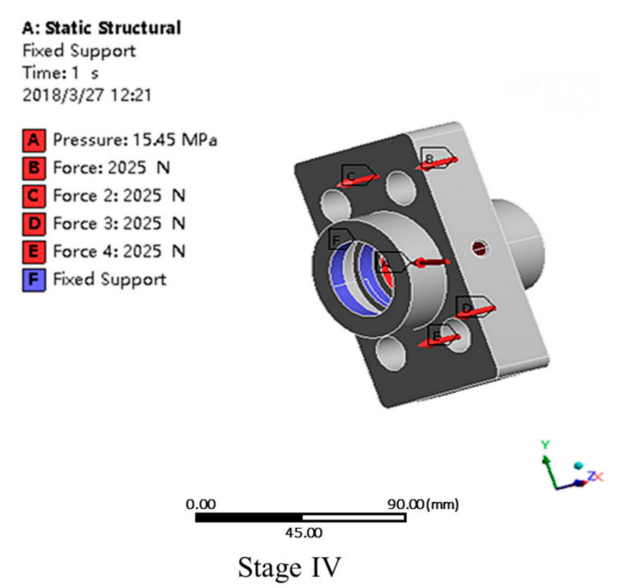

Stage IV

Figure 6. Boundary conditions of the stress analysis for the end cover. 
The knockout plate is one of the key components for transmitting power in the compressor unit. It can be treated as a slender beam, where the middle part suffers the force from nuts, which requires a high stiffness to have a minor deformation. This high stiffness guarantees the high coaxiality between the cylinder and the piston. The material of the knockout plate was designed to be aluminum alloy 7075 , which has the material properties of: elasticity modulus of $72 \mathrm{GPa}$, density of $2800 \mathrm{~kg} / \mathrm{m}^{3}$, Poisson ratio of 0.33 , and yield strength of $460 \mathrm{MPa}$. Based on the grid independence calculation presented in Table 3, the mesh number generated for the stress and stiffness analysis of the knockout plate was 83,564 in this study. As shown in Figure 7, the forces from two piston rods were set at the end of the knockout plate as the boundary condition, while the force from the nuts of the ball screw pair was set at the middle part of the knockout plate. More information of the boundary conditions for the stress analysis of the end cover and the knockout plate are shown in Table 4.

Table 3. Grid independence calculation for the knockout plate.

\begin{tabular}{ccc}
\hline \multirow{2}{*}{ Mesh Number } & \multicolumn{2}{c}{ Maximum Stress } \\
\cline { 2 - 3 } & Value (MPa) & Relative Error (\%) \\
\hline 61,982 & 83.20 & 8.70 \\
74,278 & 86.09 & 5.52 \\
83,564 & 90.54 & 0.64 \\
95,981 & 91.12 & $/$ \\
\hline
\end{tabular}

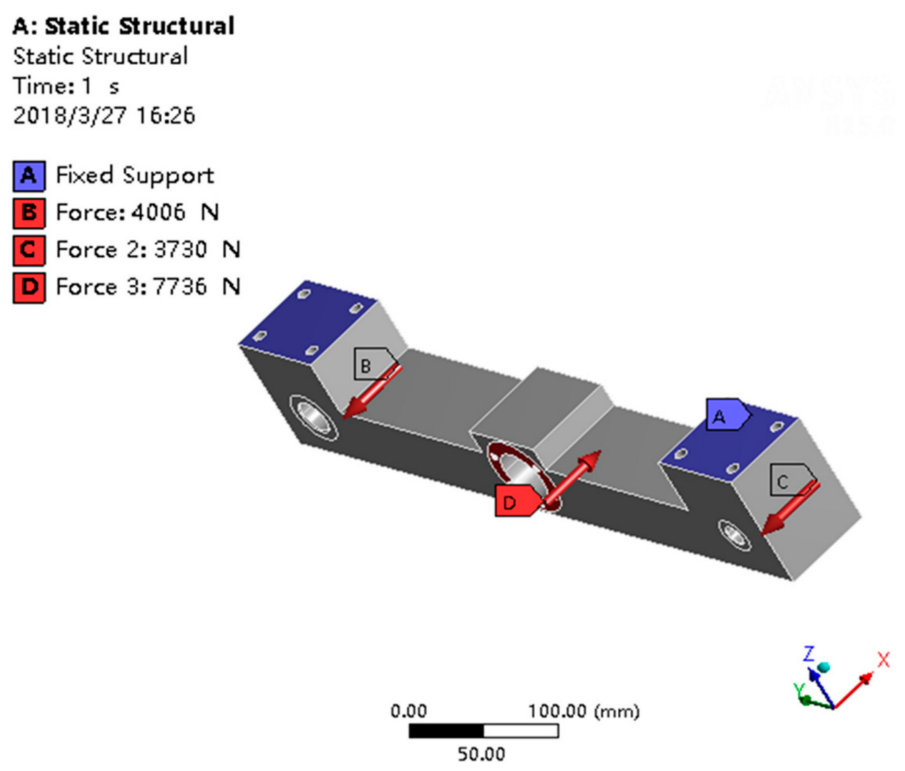

Figure 7. Boundary conditions of the stress and stiffness analysis of the knockout plate.

Table 4. Boundary conditions for the stress analysis.

\begin{tabular}{cccc}
\hline & & Boundary Condition & \\
\hline \multirow{3}{*}{ End cover } & & Screw Force (N) & Gas Pressure (MPa) \\
\cline { 2 - 4 } & Stage II & 9400 & 1.82 \\
& Stage IV & 8100 & 15.42 \\
\hline \multirow{3}{*}{ Knockout plate } & Force from the Ball & Force from the Piston & Force from the Piston \\
& Screw Unit (N) & Rod I-II (N) & Rod III-IV (N) \\
\cline { 2 - 4 } & 7736 & 4006 & 3730 \\
\hline
\end{tabular}




\section{Prototype Setup and Experimental Protocol}

\subsection{Prototype Setup and the Control System}

The prototype of the proposed unit was manufactured and built to validate the feasibility of this design and to investigate the performance of the compressor unit. As shown in Figure 8, the prototype consisted of the compressor unit and the control system. Each cylinder had two temperature sensors (CWDZ11, Beijing Star Sensor Technology Co., Ltd., Beijing, China) to measure the inlet and outlet temperature of the gas and one pressure sensor (PCM30, Suzhou Xuansheng Medical Technology Co., Ltd., Suzhou, China) to measure the outlet pressure. The temperature of the oxygen at the inlet of the gasholder was also measured using a temperature sensor to examine the cooling performance. The low-pressure oxygen gas from the oxygen-generating system was simulated and provided by an oxygen canister (WMII152-15-15A, ShanDong HuaChen High Pressure Vessel Group Co., Ltd., Jinan, China) and the pressure reduction, while another gasholder (WMII152-15-15A, ShanDong HuaChen High Pressure Vessel Group Co., Ltd., Jinan, China) was applied for the storage of the compressed oxygen gas.

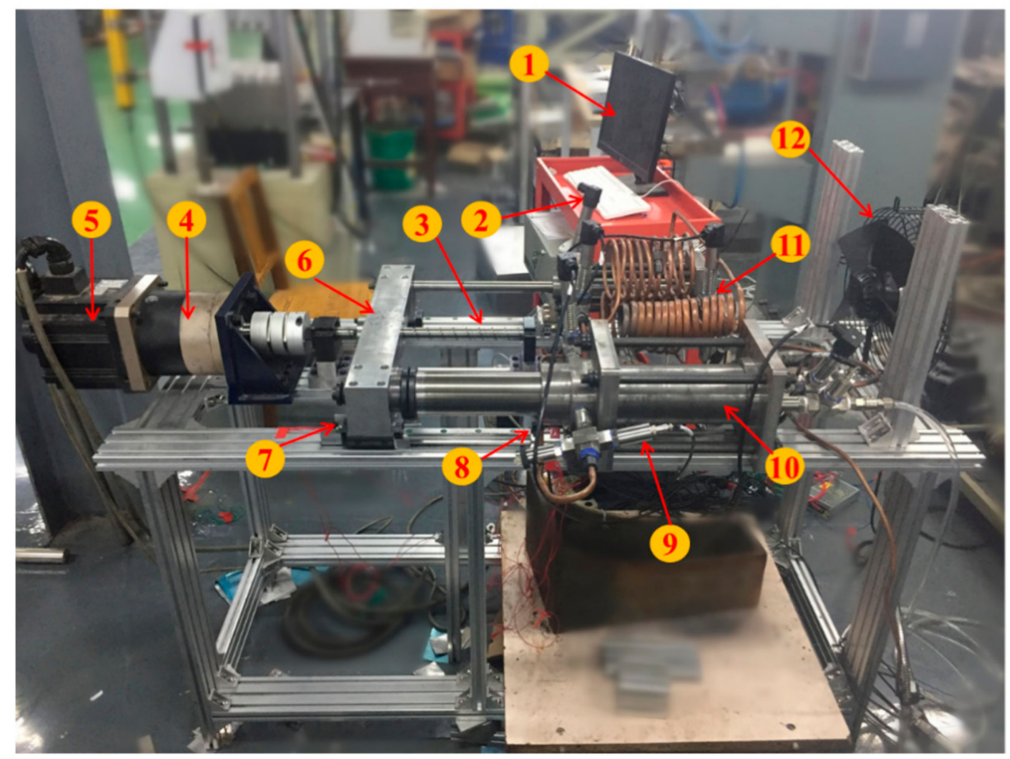

1 - Computer

2 - Pressure sensor

3 - Ball screw unit

4 - Speed reducer

5 - Servo motor

6 - Knockout plate

7 - Limit switch

8 - Origin switch

9 - Temperature Sensor

10 - Cylinder

11 - Cooling pipe

12 - Cooling fan

Figure 8. Prototype of the developed compressor unit.

The control system is one of the key parts in the compressor unit as accuracy of the motion control is a prerequisite for the successful operation of the developed system. The speed of the knockout plate needs to have a smooth variation given by the control system because the impact load is determined by the smoothness of the speed curve. The smoother the speed changes, the smaller the impact load is. Moreover, the degree of compression of the gas is determined by the maximum displacement of the piston rod. The pressure would not meet the design requirements if the maximum displacement is insufficient. In contrast, when the displacement exceeds the designed safety value, the piston rod would collide with the end cover of the cylinder, which seriously threatens the safety of the machine. Despite a limit switch being applied in the system for protection, the motion of the knockout plate should be accurately controlled by the control system to achieve the effective operation of the designed compressor system.

As shown in Figure 9, the control system for the accurate motion of the proposed unit consists of the motion control module and the online monitoring module. Both modules are in a communication state when the machine is running. 


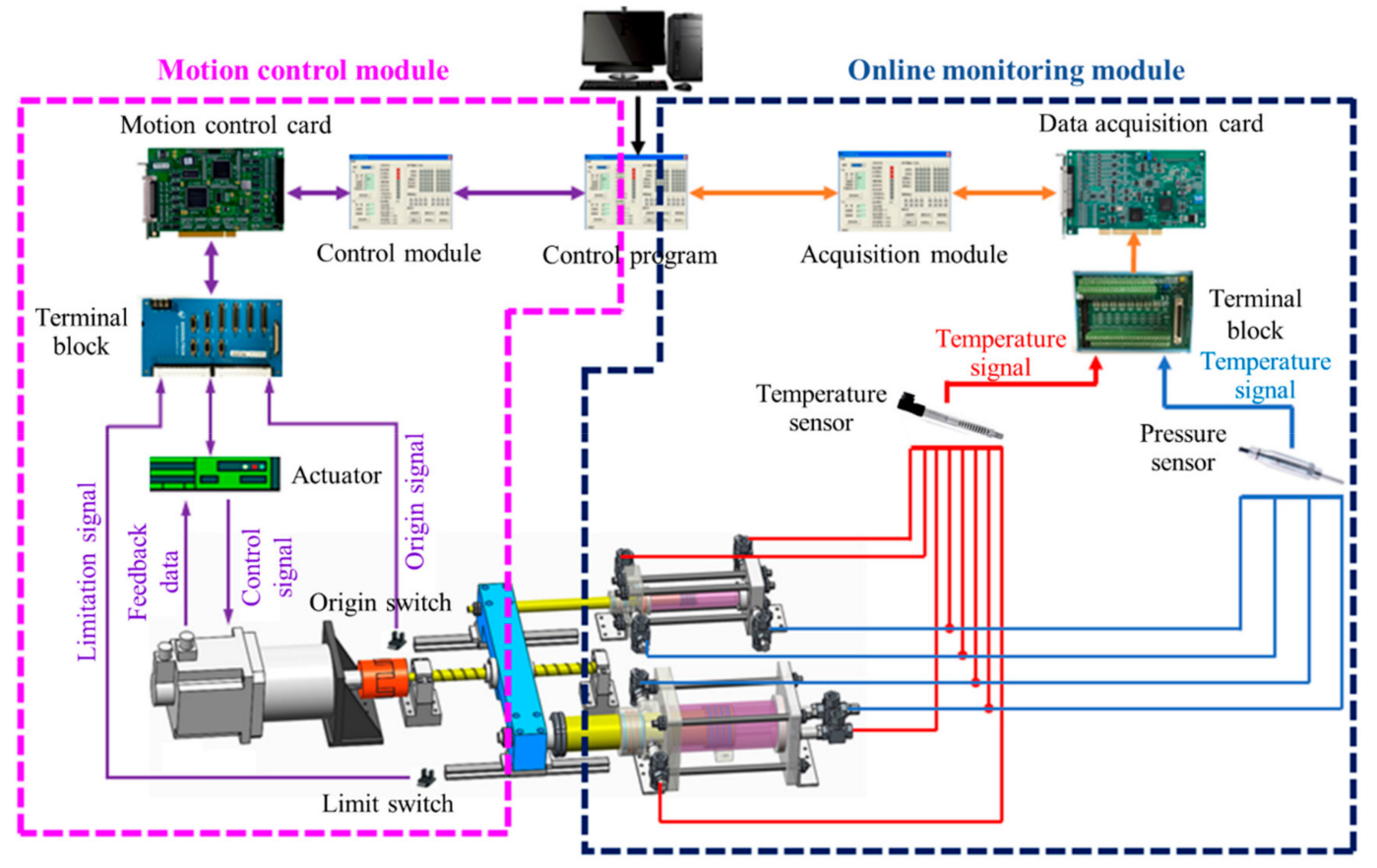

Figure 9. The control system of the developed compressor unit.

The motion control module mainly consists of the motion control card (GTS-400-PV-PCI-G, Googol Technology Limited, Shenzhen, China), the terminal block (PCLD-8710, Advantech Co., Ltd., Xi'an, China), the actuator (KSA-40/55, Xi'an Micromotor Research Institute), the limit switch (EE-SX674A, OMRON Corporation, Shanghai, China), and the origin switch (EE-SX674A, OMRON Corporation, Shanghai, China). The actuator sends the control signal to the servo motor (M130ST-03, $\mathrm{Xi}^{\prime}$ an Micromotor Research Institute) in order to control the motor rotation in a predetermined form and increase the oxygen pressure. The terminal block in the motion control module is designed to receive alarm signals, such as signals from the limit switch, galloping problem of the motor, etc., which is helpful for responding to emergencies in time. The origin switch is designed to define the origin position of the servo motor and specifies the starting point of the compression stroke. The motion control module is also designed to stop the motor immediately when it receives alarm signals of excessive pressure or temperature.

The online monitoring module mainly consists of the data acquisition card, the terminal block, the temperature sensor, and the pressure sensor. In the online monitoring module, the data of pressure and temperature in all stages are collected and saved in files where the maximum values of these parameters are chosen to send to the motion control module for consideration of the alarm signals.

In this paper, the control program integrating the motion control and online monitoring is developed in the Visual Studio 2012 MFC platform (Microsoft Corporation, Redmond, WA, USA). The flowchart of the motion control process is shown in Figure 10, which contains the functions of initialization, homing, reciprocating motion, jog motion, emergency stop, and shutdown. The initialization was implemented by pressing the start button, which established the communication between the computer and the motion control card, reset the status of the boarding card, and enabled the servo motor. The homing function meant that the servo motor was controlled to rotate to the origin point through spot movement and was prepared for the compression. The origin point was defined as the starting position of the piston in stage I. The gas compression meant that the servo motor was controlled to achieve the periodically positive inversion according to the simple harmonic motion law described by Equation (10) using the position and time (PT) motion mode. Different speed curves could be realized to meet various flow demands by adjusting the corresponding parameters of the PT 
mode. The online monitoring module worked for the initialization, data acquisition, and collection steps for the data acquisition card (PCI-1710, Advantech Co., Ltd., Xi'an, China).

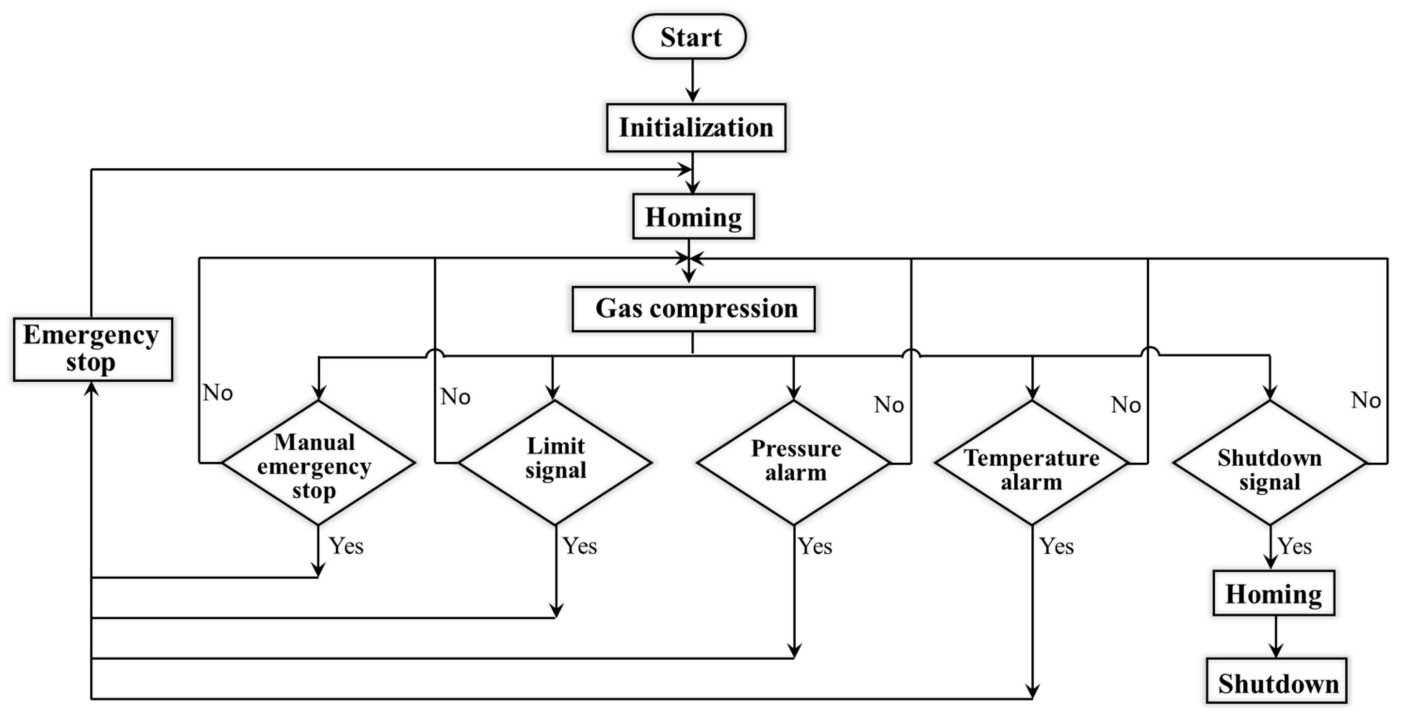

Figure 10. The flowchart of the motion control process.

\subsection{Experimental Protocol}

The experiments carried out in this paper were categorized into two groups for testing the control accuracy of the motion and the technical feasibility. The details of the operating conditions for testing the control accuracy are provided in Table 5, including three no-load experiments and one load experiment. In the no-load experiments, the suction port of the cylinder in stage I and the discharge port of the cylinder in stage IV were all opened to the atmosphere. The flow rates of the three no-load tests were 12,15 , and $18 \mathrm{~L} / \mathrm{min}$, respectively. The operating condition for the load test was the largest load in the technical feasibility experiment. The motion control accuracy was examined when the discharge pressure reached the target value and remained stable. The inlet pressure and the flow rate of the load test were designed to be $0.22 \mathrm{MPa}$ and $18 \mathrm{~L} / \mathrm{min}$, respectively.

Table 5. Experiments for testing the control accuracy of the motion.

\begin{tabular}{ccc}
\hline Load Condition & Inlet Pressure (MPa) & Flow Rate (L/min) \\
\hline \multirow{2}{*}{ No-load experiment } & $/$ & 12 \\
& $/$ & 15 \\
Load experiment & $/$ & 18 \\
\hline
\end{tabular}

The operating conditions for the technical feasibility test are summarized in Table 6 . There were three tests in this group with different inlet pressures and designed outlet pressures. The inlet pressures in the three tests were $0.18,0.2$, and $0.22 \mathrm{MPa}$, respectively, while the designed outlet pressures were $13.5,15$, and $16.5 \mathrm{MPa}$, respectively. The flow rate in the low load, standard load, and high load tests were 12,15 , and $18 \mathrm{~L} / \mathrm{min}$, respectively. In the technical feasibility tests, the pressure and temperature were recorded from the start of the compression until the exhaust pressure reached a steady state.

Table 6. Experiments for testing the technical feasibility.

\begin{tabular}{ccccc}
\hline Load Condition & Inlet Temperature $\left({ }^{\circ} \mathbf{C}\right)$ & Inlet Pressure $(\mathrm{MPa})$ & Designed Outlet Pressure (MPa) & Flow Rate $(\mathrm{L} / \mathrm{min})$ \\
\hline Low load & 20 & 0.18 & 13.5 & 12 \\
Standard load & 20 & 0.2 & 15 & 15 \\
High load & 20 & 0.22 & 16.5 & 18 \\
\hline
\end{tabular}




\section{Results and Discussions}

\subsection{Results of the Component Design}

The design results of the cylinder assemblies are summarized in Table 7 . The diameters of the cylinders in stages I and II were $90 \mathrm{~mm}$, while those in Stages III and IV were $30 \mathrm{~mm}$. The diameters of the piston rods in stages II and IV were 75 and $25 \mathrm{~mm}$, respectively. The piston stroke in all stages was $197 \mathrm{~mm}$.

Table 7. Dimension of the cylinders.

\begin{tabular}{ccccc}
\hline Parameters & I & II & III & IV \\
\hline Calculated diameter of the cylinder $(\mathrm{mm})$ & 90 & 90 & 31 & 31 \\
Calculated diameter of the piston rod $(\mathrm{mm})$ & $/$ & 73.3 & $/$ & 24.6 \\
Calculated piston stroke $(\mathrm{mm})$ & 197.3 & 197.3 & 197.3 & 197.3 \\
Rounding diameter of the cylinder $(\mathrm{mm})$ & 90 & 90 & 30 & 30 \\
Rounding diameter of the piston rod $(\mathrm{mm})$ & $/$ & 75 & $/$ & 25 \\
Rounding piston stroke $(\mathrm{mm})$ & 197 & 197 & 197 & 197 \\
\hline
\end{tabular}

The specification of the selected ball screw unit based on the design method provided in Section 3.2 is shown in Table 8. The nominal diameter and the basic lead of the ball screw were all $25 \mathrm{~mm}$, while the rated dynamic and static loads were 8221 and 17,400 N, respectively. The specification of the selected servo motor is provided in Table 9. The nominal power and voltage of the servo motor were $1.5 \mathrm{~kW}$ and $220 \mathrm{~V}$, respectively. The nominal torque of the motor was $7.16 \mathrm{~N} \cdot \mathrm{m}$, while the maximum torque was $21.5 \mathrm{~N} \cdot \mathrm{m}$. The nominal and maximum speeds of the motor were 2000 and $3000 \mathrm{rpm}$, respectively.

Table 8. Specifications of the selected ball screw unit.

\begin{tabular}{ccccc}
\hline Items & Nominal Diameter $(\mathbf{m m})$ & Basic Lead $(\mathbf{m m})$ & Nominal Dynamic Load $(\mathbf{N})$ & Nominal Static Load (N) \\
\hline Value & 25 & 25 & 8221 & 17,400 \\
\hline
\end{tabular}

Table 9. Specifications of the selected servo motor.

\begin{tabular}{ccccccc}
\hline Items & $\begin{array}{c}\text { Nominal Power } \\
(\mathbf{k W})\end{array}$ & $\begin{array}{c}\text { Nominal Voltage } \\
(\mathbf{V})\end{array}$ & $\begin{array}{c}\text { Nominal Torque } \\
\mathbf{( N \cdot m )}\end{array}$ & $\begin{array}{c}\text { Maximum Torque } \\
\mathbf{( N \cdot m )}\end{array}$ & $\begin{array}{c}\text { Nominal Speed } \\
(\mathbf{r p m})\end{array}$ & $\begin{array}{c}\text { Maximun Speed } \\
(\mathbf{r p m})\end{array}$ \\
\hline Value & 1.5 & 220 & 7.16 & 21.5 & 2000 & 3000 \\
\hline
\end{tabular}

The design results of the spiral cooling pipe are summarized in Table 10. The length of the pipes was designed to be $20 \%$ larger than the calculated value for safety. The outer and inner diameters of pipes I-II and II-III were 10 and $8 \mathrm{~mm}$, respectively, while those of pipes III-IV and IV-gasholder were 8 and $5 \mathrm{~mm}$, respectively. The helix diameters of pipes I-II and II-III were $60 \mathrm{~mm}$, while those of pipes III-IV and IV-gasholder were $75 \mathrm{~mm}$. The pitch of all pipes was designed to be $20 \mathrm{~mm}$. The number of turns for pipes I-II and III-IV was 12, and that for pipes II-III and IV-gasholder was 10.

Table 10. Specifications of the spiral cooling pipe.

\begin{tabular}{ccccc}
\hline & I-II & II-III & III-IV & IV-Gasholder \\
\hline External diameter $D_{o}(\mathrm{~mm})$ & 10 & 10 & 8 & 8 \\
Inner diameter $D_{i}(\mathrm{~mm})$ & 8 & 8 & 5 & 5 \\
Helix diameter $D_{r}(\mathrm{~mm})$ & 60 & 60 & 75 & 75 \\
Pitch $p_{t}(\mathrm{~mm})$ & 20 & 20 & 20 & 20 \\
Number of turns & 12 & 10 & 12 & 10 \\
\hline
\end{tabular}

The results of the heat transfer analysis for the spiral cooling pipes are summarized in Table 11. It was found that the outlet temperature of the last spiral cooling pipe IV-gasholder was $30{ }^{\circ} \mathrm{C}$, which was lower than the inlet temperature by $8{ }^{\circ} \mathrm{C}$. 
Table 11. Results of the heat transfer analysis for the spiral cooling pipe.

\begin{tabular}{ccccc}
\hline & I-II & II-III & III-IV & IV-Gasholder \\
\hline Inlet temperature $\left({ }^{\circ} \mathrm{C}\right)$ & 165 & 164 & 159 & 158 \\
Outlet temperature from CFD analysis $\left({ }^{\circ} \mathrm{C}\right)$ & 32 & 30 & 32 & 30 \\
\hline
\end{tabular}

\subsection{Results of the Stress Analysis}

The results of the stress analysis of the end cover for stages II and IV are shown in Figure 11. It was found that the maximum stress of the end cover for stage II was $41.86 \mathrm{MPa}$, which was located at the inner circular surface. This was caused by the preload force from the bolts and the fixed constraint boundary condition. The maximum stress of the end cover for stage IV was found to be $75.37 \mathrm{MPa}$ located at the junction of the flange and the ring place, which was also caused by the bolt preload. The stress of the surface for the inner cavity of the end cover for stage IV was significantly larger than that for stage II due to the high oxygen pressure. The maximum deformation of the end covers for both stages II and IV was around $0.02 \mathrm{~mm}$ and located at the four corners of the flange. The deformation of the surface for the inner cavity was found to be extremely small, where the airtightness could be maintained being operational with the sealing element. Similarly, the maximum stresses of the end cover for stages I and III were obtained to be 73.60 and $76.64 \mathrm{MPa}$, respectively, while the maximum deformations were 0.06 and $0.01 \mathrm{~mm}$, respectively. This means that the stress and the stiffness of the designed end covers were able to satisfy the application demand.

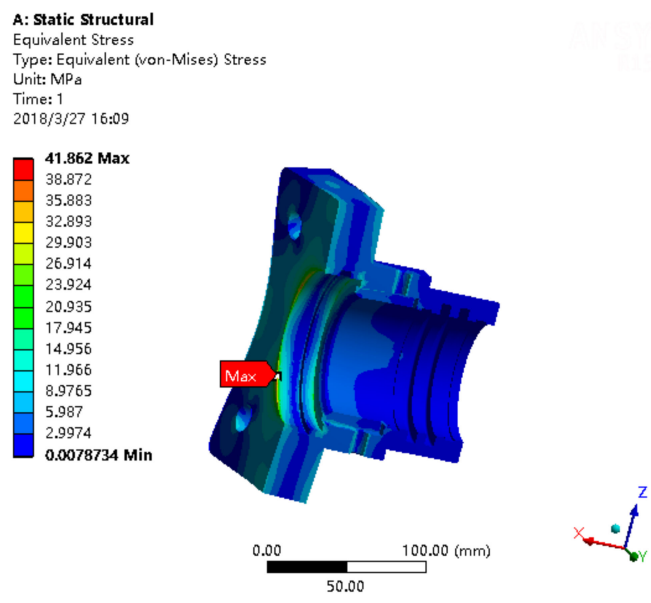

(a) Stress distribution of the end cover for stage II

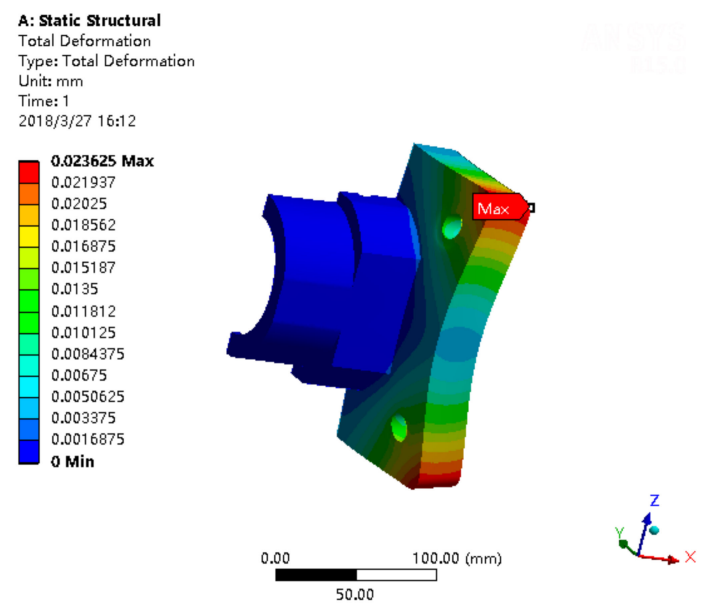

(b) Deformation distribution of the end cover for stage II

Figure 11. Cont. 


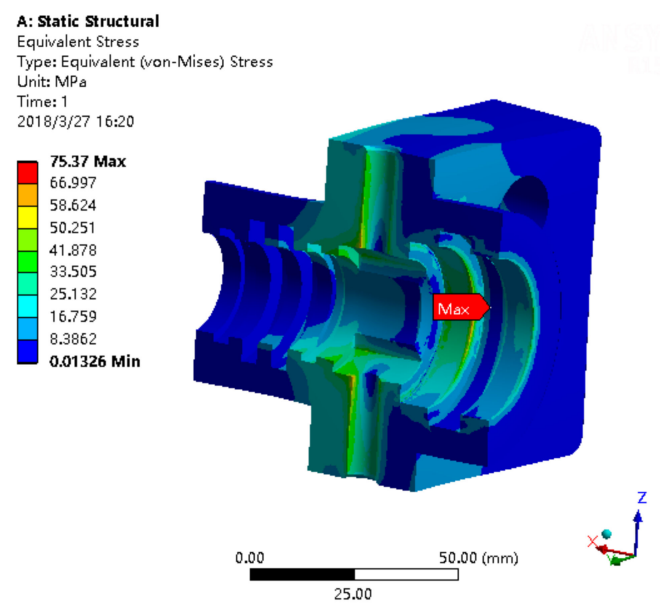

(c) Stress distribution of the end cover for stage IV

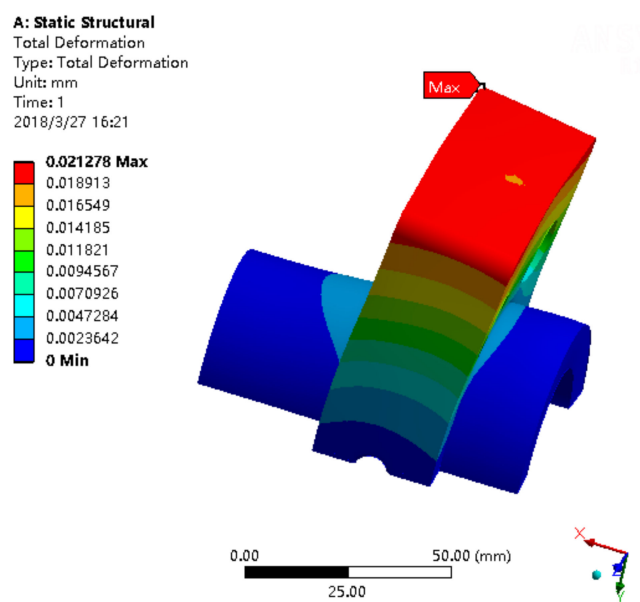

(d) Deformation distribution of the end cover for stage IV

Figure 11. Stress and deformation distributions of the end covers for stages II and IV.

The results of the stress analysis for the knockout plate is shown in Figure 12. Both the maximum stress and the maximum deformation were located in the middle part of the knockout plate, which was fitted with the ball screw nut. This was caused by the axial force from the screw nut. The maximum stress was found to be $90.54 \mathrm{MPa}$, which was less than the allowable bending stress of $707 \mathrm{MPa}$ for a 7075 aluminum alloy. The maximum deformation was only $0.1 \mathrm{~mm}$ and the region matched with the piston rod had a negligible deformation. This indicated that the deformation would not affect the effective movement of the piston rod.

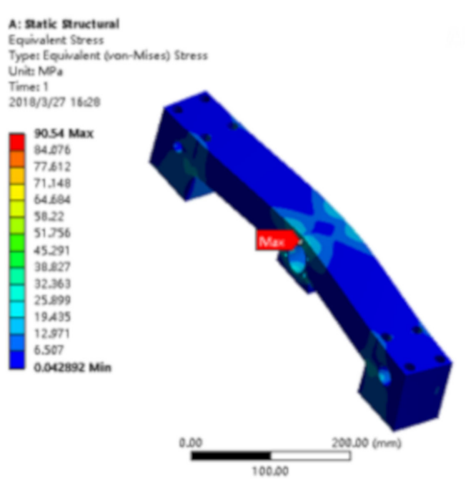

(a)

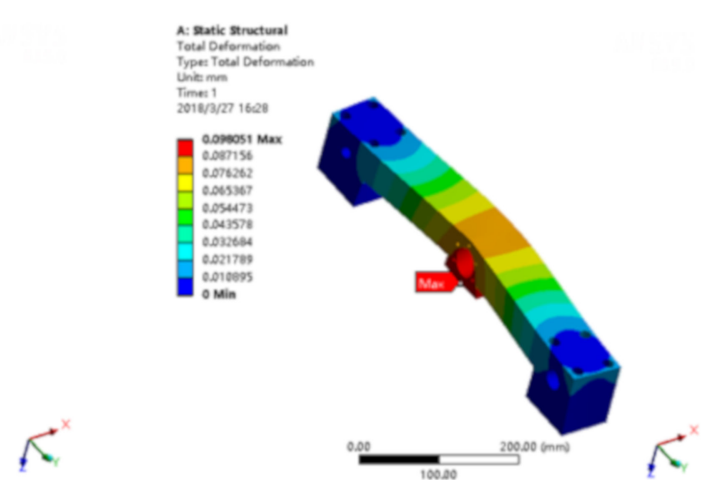

(b)

Figure 12. (a) Stress distribution and (b) deformation distribution of the knockout plate. 


\subsection{Results of the Experiments for Testing the Control Accuracy}

The experiments for testing the control accuracy included the no-load experiment and the load experiment. In the no-load experiment, the planned rotational speed of the motion control card, the real-time rotational speed, and the real-time angular displacement from the motor encoder were all recorded for the analysis. The variations of the speed and the angular displacement of the servo motor under different flow rates are illustrated in Figure 13. It was found that the fluctuation of the planned speed decreased with the increase in the flow rate (see Figure 13a,c,e), which means that the control accuracy was higher under a high flow rate. It was also found that the variation of the real-time speed of the servo motor presented a smooth and simple harmonic motion, and the maximum control error under the maximum speed was less than $2 \%$. The results showed that the curve of the planned angular displacement matched well with the real-time value in all no-load experiments, which indicated that a high control accuracy was obtained under the no-load conditions.

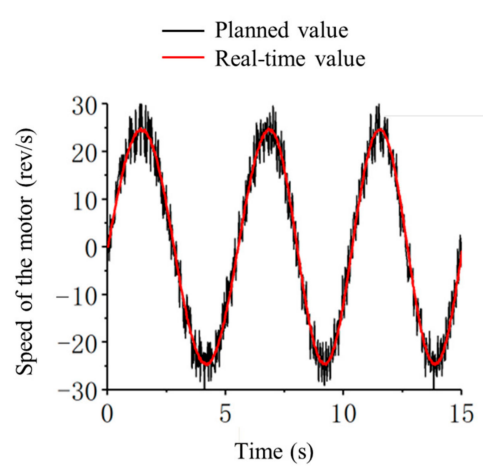

(a) Variation of the speed under the flow rate of $12 \mathrm{~L} / \mathrm{min}$

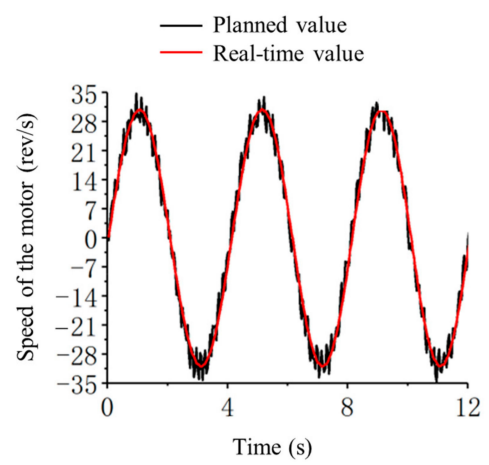

(c) Variation of the speed under the flow rate of $15 \mathrm{~L} / \mathrm{min}$

_ Planned value

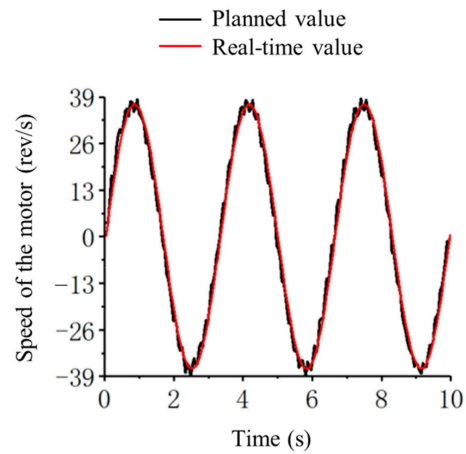

(e) Variation of the speed under the flow rate of $18 \mathrm{~L} / \mathrm{min}$

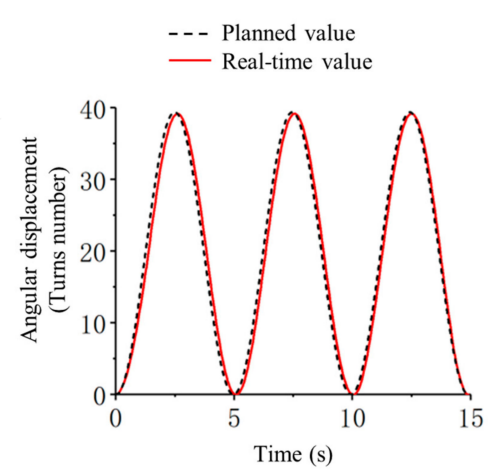

(b) Variation of the angular displacement under the flow rate of $12 \mathrm{~L} / \mathrm{min}$

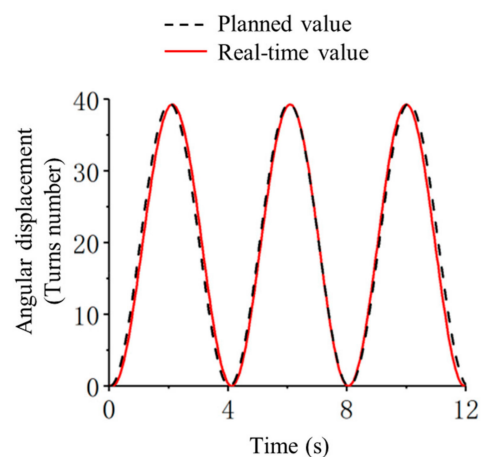

(d) Variation of the angular displacemen under the flow rate of $15 \mathrm{~L} / \mathrm{min}$

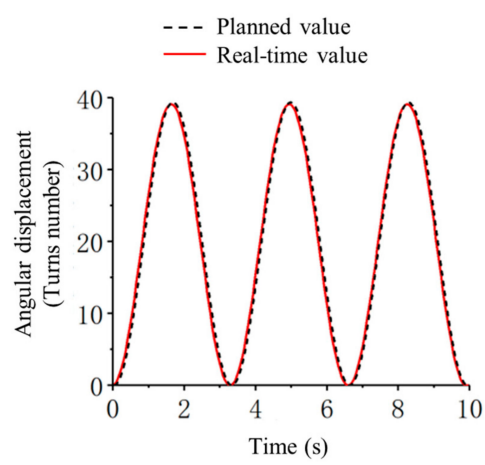

(f) Variation of the angular displacement under the flow rate of $18 \mathrm{~L} / \mathrm{min}$

Figure 13. Variation of the speed and angular displacement in the no-load experiments. 
The variation of the speed and angular displacement in the load experiment is shown in Figure 14. It was found that the fluctuation in the load experiment was smaller than that in all the no-load experiments, which means the control accuracy was improved in the load experiment. Figure 14b shows that the curve of the real-time angular displacement was in line with the planned curve. The control errors of the motion period, the maximum speed, and the maximum angular displacement were all less than $2 \%$.

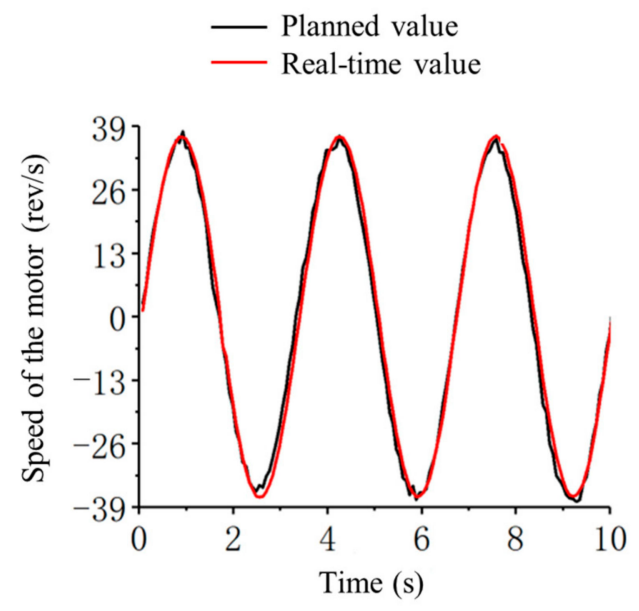

(a)

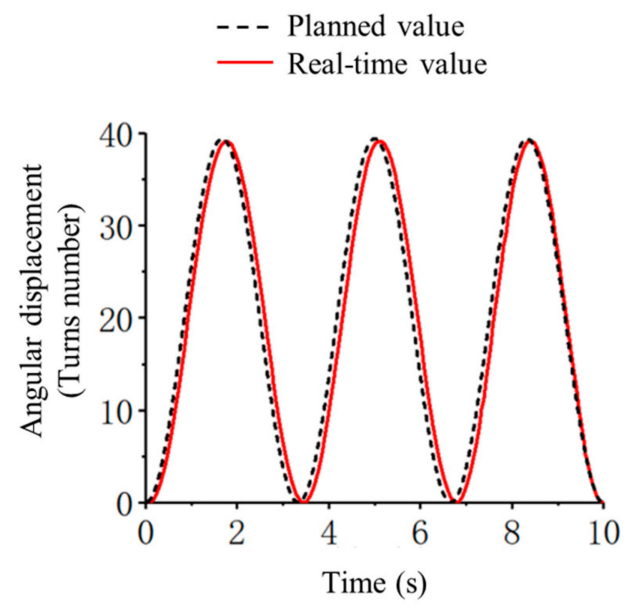

(b)

Figure 14. Variation of the (a) speed and (b) angular displacement in the load experiment.

The experiments for testing the control accuracy of motion proved that the motion control program designed in this paper was able to realize the motion scheme of the compressor.

\subsection{Results of the Experiments for Testing the Technical Feasibility}

\subsubsection{Results under Standard Working Conditions}

The variations of the measured and average discharge pressure in all stages under the standard load are shown in Figure 15. The discharge pressure increased and became stable after around 40 cycles of the compression. The fluctuation of the discharge pressure was observed due to the low volume flow rate and the low frequency of the compressor. The fluctuation in stage I was more regular compared to the other three stages, which was probably because the suction pressure in stage I was more stable compared to the others. The average discharge pressure was used to indicate the pressure performance for the analysis and comparison, which was the mean value of the measured pressure at this cycle and the prior cycle. The average discharge pressure in stages I-IV reached around 0.57, 1.88, 5.10, and 15.70, respectively. The average discharge pressure in stage IV was higher than the designed value (15 MPa); this means that the designed compressor could reach the pressure requirement under standard working conditions.

To compare the increase rate of the discharge pressure and the relative error between the designed and the measured discharge pressure, the discharge pressures and the relative errors in all stages are provided in Figure 16. It can be found in Figure 16a that the highest absolute value of the amplitude of the fluctuation of the discharge pressure was found in stage IV. This might have been because all fluctuations were accumulated in the last stage as every stage had its own fluctuation. Figure $16 \mathrm{~b}$ shows that the largest relative error between the measured and designed values of the discharge pressure was $6.9 \%$ in stage II, while the lowest was $1.9 \%$ in stage III.

The results of the measured inlet and discharge temperatures are shown in Figure 17. The temperature was observed to be stable after around 100 compression cycles. The inlet temperature in stage I was around $20^{\circ} \mathrm{C}$ during all the time, while the inlet temperature in stage IV increased to around $26^{\circ} \mathrm{C}$ after 100 cycles. The inlet temperature of the gasholder reached around $25^{\circ} \mathrm{C}$ when 
it was stable. It was also found that the discharge temperature was in the range of $67-73{ }^{\circ} \mathrm{C}$ after 100 cycles. The discharge temperature in stage III was the lowest before around 20 cycles, but it was higher than that of stages I and II after the 70th cycle. This was probably because the temperatures of all the cylinders were low when the experiment started, and was therefore able to cool the compressed oxygen. During the same time, the cylinders were heated by the compressed oxygen. Therefore, the difference in the discharge temperatures between the different stages was able to remain relatively stable when the inlet temperature of the oxygen became stable.

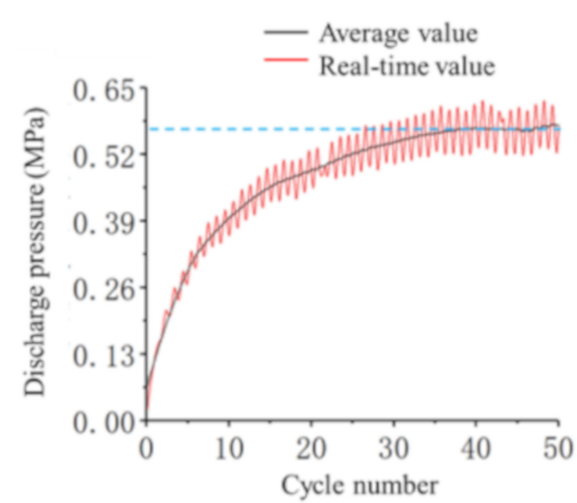

(a) Stage I

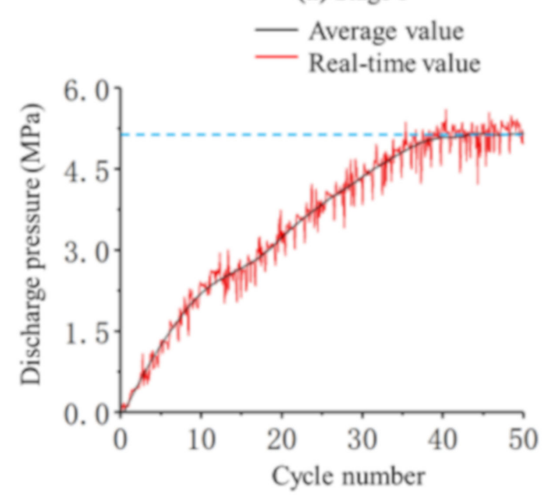

(c) Stage III

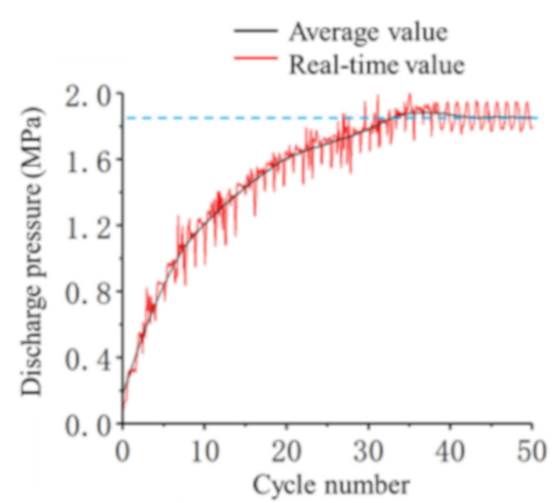

(b) Stage II

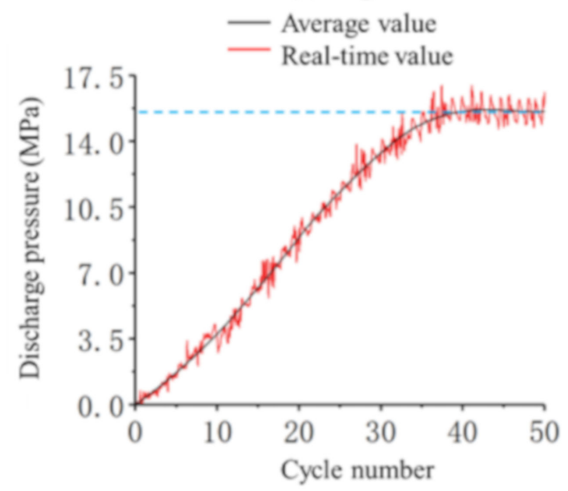

(d) Stage IV

Figure 15. Variation of the discharge pressure with the increase in the cycle number.

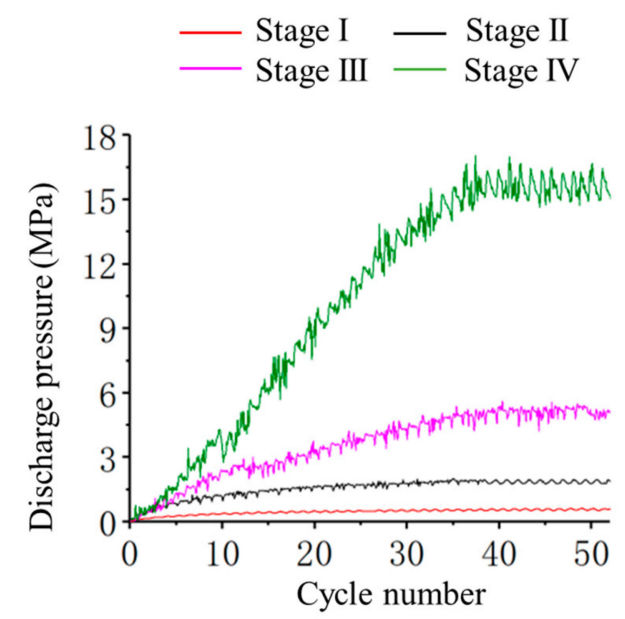

(a)

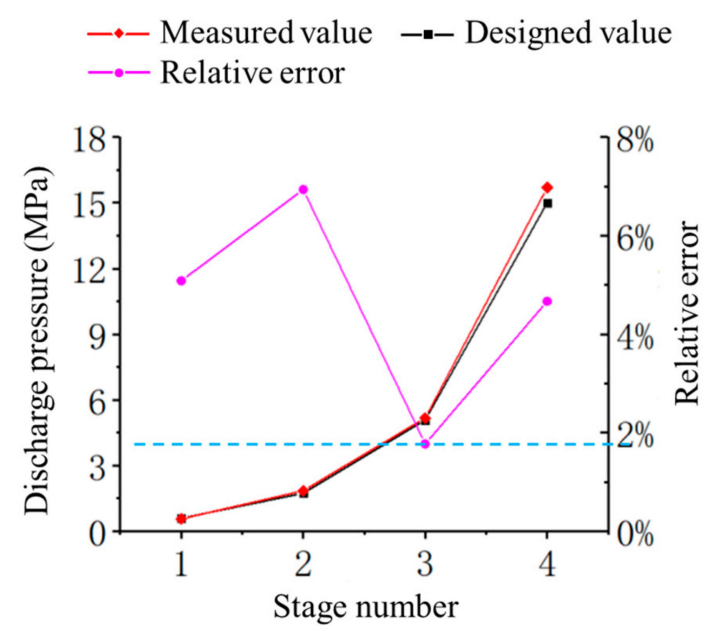

(b)

Figure 16. Comparison of (a) the discharge pressures and (b) the relative errors in all stages. 


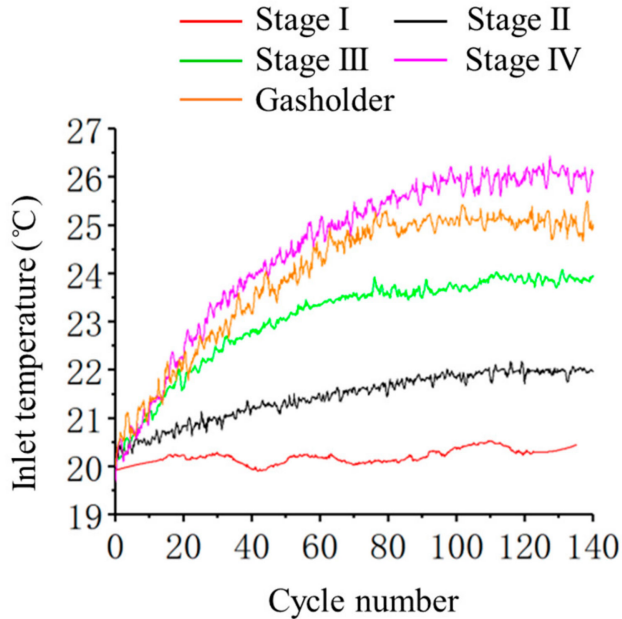

(a)

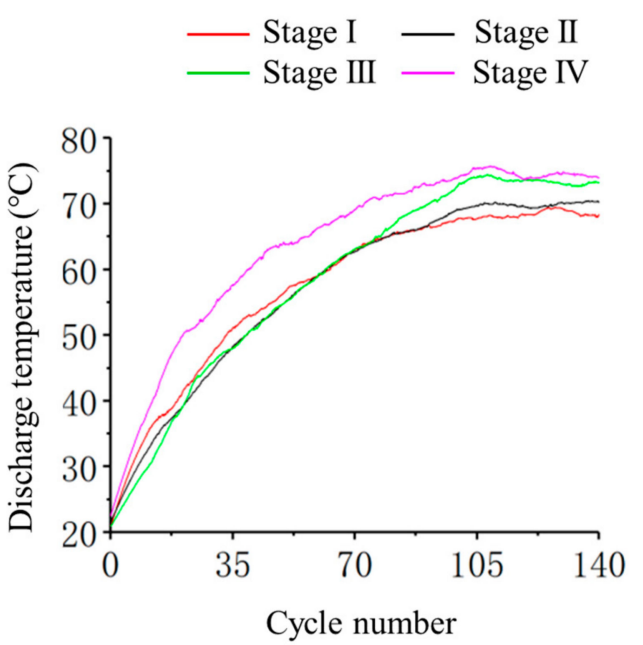

(b)

Figure 17. (a) Inlet and (b) discharge temperatures in all stages.

\subsubsection{Results under the Non-Standard Working Conditions}

The measured discharge pressures in all stages under the non-standard working conditions are shown in Figure 18. The discharge pressures in all stages also became relatively stable after around 40 cycles under the non-standard working conditions. The average discharge pressure in stage III under the low load was around 6.0 MPa, which was close to that under the high load (5.9 MPa). The average discharge pressure in stage IV under the low load was $14.1 \mathrm{MPa}$, while it was $17.1 \mathrm{MPa}$ under the high load. The fluctuation frequency and the increased rate of the discharge pressure under the high load were both higher than those under the low load condition.

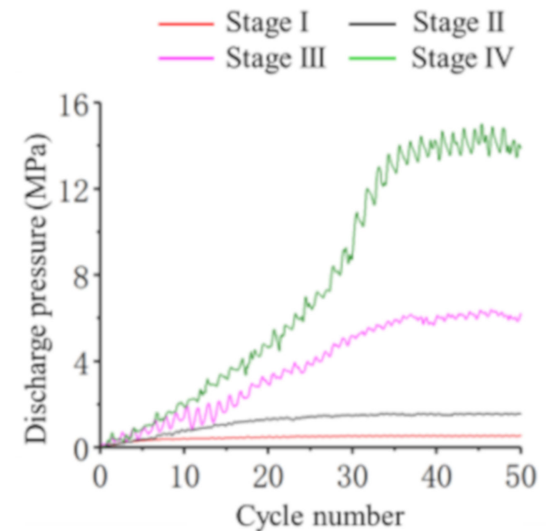

(a) Low load

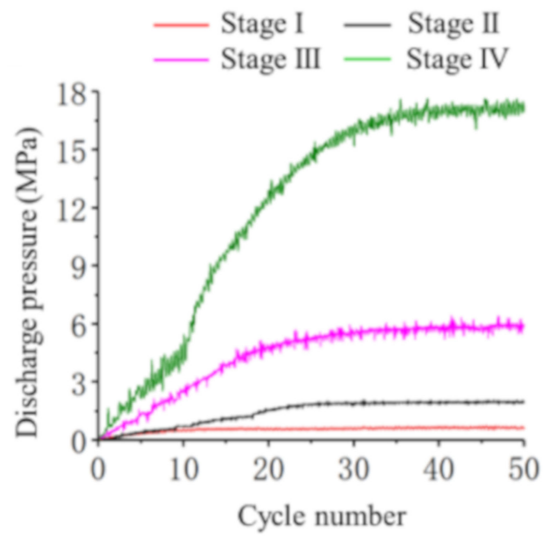

(b) High load

Figure 18. Discharge pressures in all stages under non-standard working conditions.

The results of the inlet and discharge temperatures in all stages under the low load are shown in Figure 19. Similar to that under the standard condition, the inlet temperatures became stable after 100 cycles. The inlet temperature of stage IV and the gasholder were observed to be around 25 and $22.5^{\circ} \mathrm{C}$, respectively. It was also found that the discharge temperatures in all stages were in the range of $65-72{ }^{\circ} \mathrm{C}$. The discharge temperature in stage IV was the lowest until the 77 th cycle, after which it increased quickly and reached close to that in stage III. 


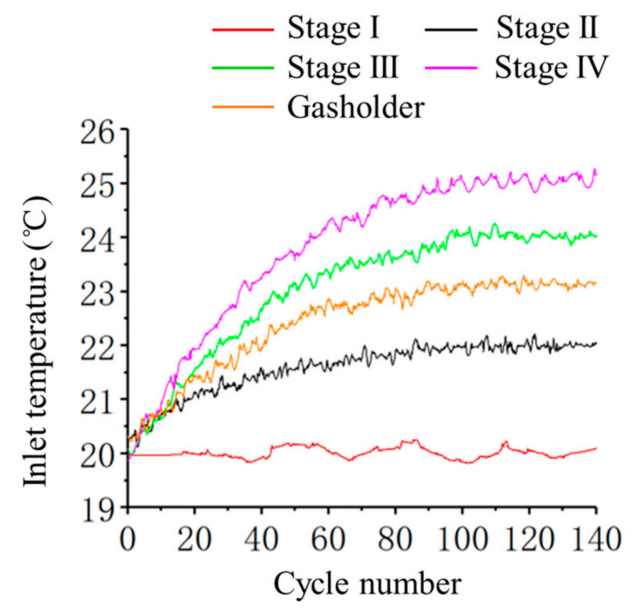

(a)

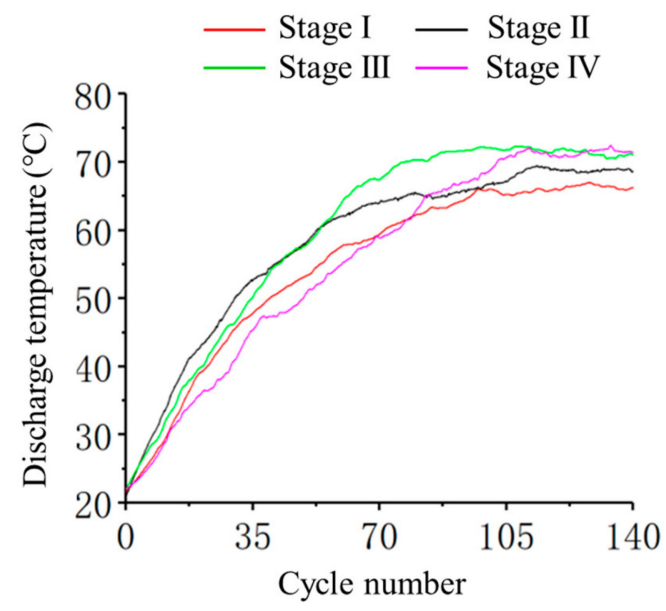

(b)

Figure 19. The (a) inlet temperature and (b) discharge temperature under the low load.

The measured inlet and discharge temperatures under the high load condition are illustrated in Figure 20. The inlet temperatures in stages II and the gasholder were close to each other during the whole process, which means that the heat generated by the gas compression in stages II, III, and IV were successfully discharged through the designed fan and spiral cooling pipe under the high load. During the stable cycles, the inlet temperature in stages IV and the gasholder were found to be around 26 and $24^{\circ} \mathrm{C}$, respectively. The results also showed that the discharge temperature in stage III was the highest compared to that of the rest of the stages all the time during the experiment, which increased up to around $76^{\circ} \mathrm{C}$ when it became stable. The discharge temperatures in the other three stages were found in the range of $68-75{ }^{\circ} \mathrm{C}$ when they achieved relative stability.

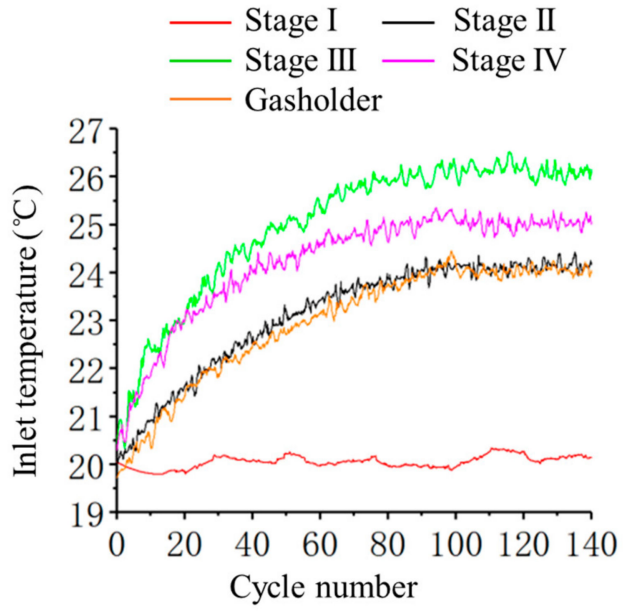

(a)

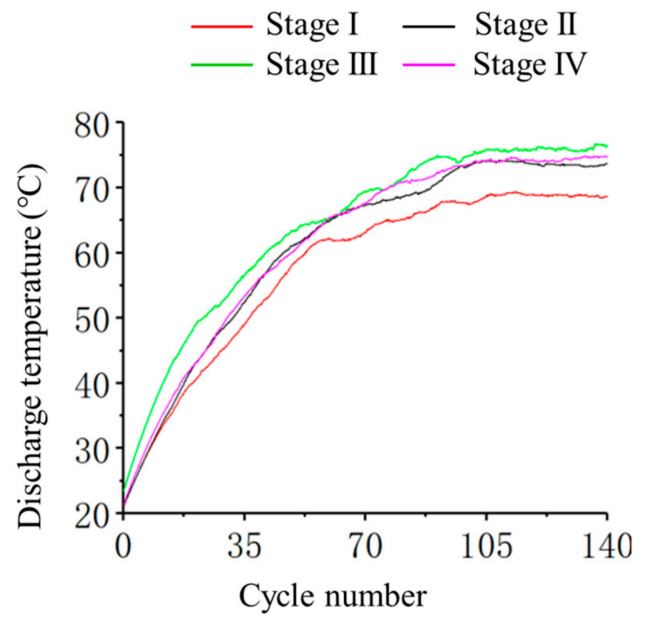

(b)

Figure 20. The (a) inlet temperature and (b) discharge temperature under the high load.

\subsubsection{Comparison between the Experimental Results and the Designed Values}

A comparison between the experimental results and the designed values calculated using the mathematical model under different working conditions is provided in Table 12. The output pressure at the last stage was always higher than the designed values with a relative error of less than $5 \%$ under all different working conditions. This means that the designed compressor could meet the compression requirement for the application demand. 
Table 12. Comparison between the experimental results and the designed values.

\begin{tabular}{cccc}
\hline & Low Load & Standard Load & High Load \\
\hline Experimental output pressure at the last stage (MPa) & 14.1 & 15.7 & 17.1 \\
Designed output pressure at the last stage (MPa) & 13.5 & 15 & 16.5 \\
Relative error & $4.4 \%$ & $4.7 \%$ & $3.8 \%$ \\
\hline
\end{tabular}

\subsubsection{Comparison between Different Working Conditions}

The comparison of the temperatures and compression exponents between different load conditions are provided in Figure 21. The results showed that all the inlet temperatures were below $27^{\circ} \mathrm{C}$, while the discharged temperatures were in the range of $67-76^{\circ} \mathrm{C}$. Although the inlet temperatures in stage IV under all load conditions were almost the same as each other, the lowest discharge temperature in stage IV was obtained under the standard load, while the highest value was observed under the high load. This might have been because the compression heat generated under the standard condition was able to be discharged during the internal cooling in the spiral pipe. The compression exponent varied between 1.156-1.168 under the different load conditions. The compression exponent under the high load condition increased with the increase in the stage number, while that in the other two conditions increased first and then decreased. The highest compression exponents in all four stages were found in the high load condition. Furthermore, the compression exponent in stage IV under the standard load was found close to that under the low load.

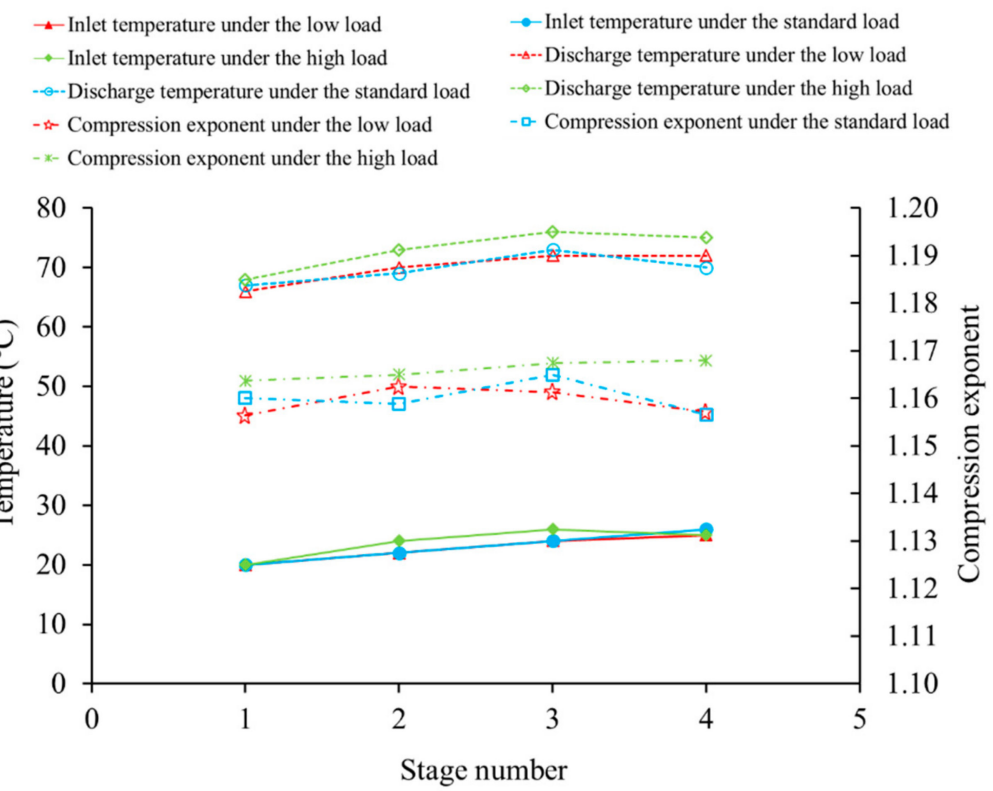

Figure 21. Comparison of the temperatures and compression exponent between different load conditions.

\section{Conclusions}

This paper proposed a multistage compressor unit with a servo motor and ball screw unit that replaced the conventional crank mechanism for an OBOGS. The control accuracy and the technical feasibility in terms of the compression capacity and the cooling performance of the proposed compressor unit were experimentally investigated. The main conclusions that can be drawn from the experimental results of the prototype are as follows.

The control errors of the motion period, the maximum speed, and the maximum angular displacement were all less than $2 \%$, which means that the motion control program was able to realize the motion scheme of the compressor unit. 
The discharge pressure reached relative stability after around 40 cycles of compression, while the discharge temperature achieved relative stability after approximately 100 cycles under both the standard and non-standard working conditions.

The average discharge pressure at the last stage reached $15.7 \mathrm{MPa}$, while the inlet temperature of the oxygen to the gasholder was $25^{\circ} \mathrm{C}$ under the standard working condition. The average discharge pressures under the low and high loads were found to be 14.1 and $17.1 \mathrm{MPa}$, respectively. The average inlet temperature of the oxygen gas holder was found to be $22.5^{\circ} \mathrm{C}$ under the low load condition, while that under the high load was found to be $24^{\circ} \mathrm{C}$.

The compression exponent varied between 1.156-1.168 under different load conditions with the highest compression exponents found in the high load condition. The compression exponent under the high load condition increased with the increase in the stage number, while that in the other two conditions increased first and then decreased.

Author Contributions: Conceptualization, Y.G., Y.W. and S.Z.; methodology, Y.G. and S.Z.; software, Y.W. and B.L.; investigation, Y.G., Y.W. and B.L.; writing-original draft preparation, Y.G. and Y.W.; writing-review and editing, Y.G. and S.Z. All authors have read and agreed to the published version of the manuscript.

Funding: This research was funded by the Fundamental Research Funds for the Central Universities, grant number XZY012019003 and XJH012019010; the China Postdoctoral Science Foundation, grant number 2018M 643627; and the Natural Science Basic Research Plan in Shaanxi Province of China, grant number 2019JQ-602.

Conflicts of Interest: The authors declare no conflict of interest.

\section{Abbreviations}

Nomenclature

A $\quad$ area $\left(\mathrm{dm}^{2}\right)$

$\underline{a_{S M}} \quad$ angular acceleration of the servo motor $\left(\mathrm{rad} / \mathrm{s}^{2}\right)$

$\overline{C_{p}} \quad$ average specific heat capacity $(\mathrm{J} / \mathrm{kg} \cdot \mathrm{K})$

$D \quad$ diameter of the cylinder $(\mathrm{dm})$

$D_{o} \quad$ external diameter of the spiral cooling pipe (m)

$D_{r} \quad$ diameter of the pipe cylinder $(\mathrm{m})$

$\mathrm{d} \quad$ diameter of the piston rod $(\mathrm{dm})$

$F_{a} \quad$ preload force $(\mathrm{N})$

$\mathrm{F}_{B S} \quad$ load on the ball screw (N)

$F_{G} \quad$ gas force (N)

$F^{\prime \prime} \quad$ residual force from the bolts $(\mathrm{N})$

h heat transfer coefficient $\left(\mathrm{W} /\left(\mathrm{m}^{2} \mathrm{~K}\right)\right)$

I reduce ratio

J rotating inertia $\left(\mathrm{kg} \cdot \mathrm{dm}^{2}\right)$

L length (m)

$\mathrm{m} \quad$ mass $(\mathrm{kg})$

$\mathrm{N} \quad$ rotational speed (rpm)

n safety factor

$n_{T} \quad$ isentropic temperature exponent

$n_{V} \quad$ isentropic volume exponent

$\mathrm{P} \quad$ pressure $(\mathrm{MPa})$

$P_{h} \quad$ screw lead $(\mathrm{dm})$

$P_{t} \quad$ pitch (m)

Q heat transfer rate $(\mathrm{W})$

$q_{m} \quad$ mass flow rate $(\mathrm{kg} / \mathrm{s})$

$q_{v} \quad$ volumetric flow rate $(\mathrm{L} / \mathrm{min})$

$r_{1} \quad$ inner radius of the cylinder $(\mathrm{dm})$

$r_{2} \quad$ external radius of the cylinder $(\mathrm{dm})$

$\mathrm{S} \quad$ piston stroke $(\mathrm{dm})$

$\mathrm{T}$ temperature (K)

$T_{S M} \quad$ torque of the servo motor $(\mathrm{N} \cdot \mathrm{dm})$ 


\begin{tabular}{|c|c|}
\hline$t_{c}$ & time of one compression cycle (s) \\
\hline$U$ & heat transfer efficient $\left(\mathrm{W} / \mathrm{m}^{2} \cdot \mathrm{K}\right)$ \\
\hline $\mathrm{u}$ & velocity of the air (m/s) \\
\hline V & volume (L) \\
\hline $\mathrm{v}$ & velocity of the piston $(\mathrm{dm} / \mathrm{s})$ \\
\hline$x$ & displacement of the piston $(\mathrm{dm})$ \\
\hline $\mathrm{Z}$ & compressibility value \\
\hline \multicolumn{2}{|c|}{ Greek symbols } \\
\hline$\alpha$ & relative clearance volume \\
\hline$\delta$ & length of the clearance volume (dm) \\
\hline$\varepsilon$ & pressure ratio \\
\hline$\eta$ & transmission efficiency \\
\hline$\lambda$ & thermal conductivity $(\mathrm{W} / \mathrm{m} \cdot \mathrm{K})$ \\
\hline$\lambda_{l}$ & leakage coefficient \\
\hline$\lambda_{p}$ & pressure coefficient \\
\hline$\lambda_{T}$ & temperature coefficient \\
\hline$\lambda_{v}$ & volume coefficient \\
\hline$\mu$ & dynamic viscosity $(\mathrm{Pa} \cdot \mathrm{s})$ \\
\hline$\vartheta$ & kinematic viscosity $\left(\mathrm{m}^{2} / \mathrm{s}\right)$ \\
\hline$v$ & specific volume (L/kg) \\
\hline$\rho$ & density $\left(\mathrm{kg} / \mathrm{m}^{3}\right)$ \\
\hline$\sigma_{\operatorname{amax}}$ & maximum axial stress $(\mathrm{MPa})$ \\
\hline$\left[\sigma_{b}\right]$ & allowable stress $(\mathrm{MPa})$ \\
\hline$\sigma_{\mathcal{C}}$ & combined stress $(\mathrm{MPa})$ \\
\hline$\sigma_{\text {rmax }}$ & maximum radial stress $(\mathrm{MPa})$ \\
\hline$\sigma_{s}$ & yield strength (MPa) \\
\hline$\sigma_{\operatorname{tmax}}$ & maximum tangential stress (MPa) \\
\hline \multicolumn{2}{|c|}{ Subscript } \\
\hline BS & ball screw \\
\hline $\mathrm{CF}$ & cooling fan \\
\hline $\mathrm{COF}$ & counterflow \\
\hline$D S$ & downstream \\
\hline d & discharge \\
\hline $\mathrm{i}$ & inner \\
\hline $\mathrm{k}$ & stage \\
\hline $\mathrm{o}$ & external \\
\hline SK & stroke \\
\hline SM & servo motor \\
\hline SR & speed reducer \\
\hline s & suction \\
\hline
\end{tabular}

\section{References}

1. Wang, H.; Fang, L. Simulation on performance and effects of parameters analysis on three-bed OBOGS. J. Beijing Univ. Aeronaut. Astronaut. 2011, 37, 717-722. [CrossRef]

2. Gertler, J. Out of Breath: Military Aircraft Oxygen Issues. Available online: https://fas.org/sgp/crs/weapons/ IN10723.pdf (accessed on 20 May 2018).

3. Haswell, M.S.; Tacker, W.A.; Balldin, U.I.; Burton, R.R. Influence of inspired oxygen concentration on acceleration atelectasis. Aviat. Space Environ. Med. 1986, 57, 432-437. [CrossRef] [PubMed]

4. Manatt, S.A. Onboard oxygen generation systems. Aviat. Space Environ. Med. 1981, 52, 645-653. [PubMed]

5. Bhat, A.A.; Mang, H.; Rajkumar, S.; Kotresh, T.M.; Singh, U.K. On-Board Oxygen Generation Using High Performance Molecular Sieve. Def. Life Sci. J. 2017, 2, 380-384. [CrossRef]

6. Yan, W.U.; Lin, G.P. Modeling and Numerical Simulation of Onboard Molecular Sieve Oxygen Generation System. Trans. Nanjing Univ. Aeronaut. Astronaut. 2004, 21, 47-52. [CrossRef] 
7. Yang, F.; Lin, G.; Zhao, J. Nonisothermal Adsorption Model for Molecular Sieve Oxygen Concentrator(MSOC). J. Beijing Univ. Aeronaut. Astronaut. 2002, 28, 8-11. [CrossRef]

8. Sathiyaseelan, A. Military aircraft oxygen system. IOSR JMCE 2014, 7, 61-65.

9. Ghoreishi Seyyed, M.; Hoseini Dastgerdi, Z.; Dadkhah Ali, A. Numerical Analysis and Optimization of Oxygen Separation from Air via Pressure Swing Adsorption. Chem. Prod. Process Model. 2011, 6, 1934-2659. [CrossRef]

10. Jiang, D.; Sun, B.; Lin, G.; Bu, X.; Zhao, H. Analysis on water content of product gas in onboard oxygen generation system (OBOGS). In Proceedings of the IEEE International Conference on Aircraft Utility Systems, Beijing, China, 10-12 October 2016; pp. 340-345.

11. Jiang, D.; Bu, X.; Sun, B.; Lin, G.; Zhao, H.; Cai, Y.; Fang, L. Experimental study on ceramic membrane technology for onboard oxygen generation. Chin. J. Aeronaut. 2016, 29, 863-873. [CrossRef]

12. Horstman, R.H.; Lin, C.-H. Oxygen Generating System. U.S. Patent 9,089,721 B1, 28 July 2015.

13. Hamlin, H.A.S. Aircraft Aircrew Life Support Systems. U.S. Patent 4960119, 2 October 1990.

14. Ogawa, K.; Inagaki, Y.; Ohno, A. Numerical analysis of $\mathrm{O} 2$ concentration, gas-zeolite temperatures in two zeolite columns for an oxygen concentrator. Int. J. Heat Mass Transf. 2019, 129, 238-254. [CrossRef]

15. Reddy, H.V.; Bisen, V.S.; Rao, H.N.; Dutta, A.; Garud, S.S.; Karimi, I.A.; Farooq, S. Towards energy-efficient LNG terminals: Modeling and simulation of reciprocating compressors. Comput. Chem. Eng. 2019, 128, 312-321. [CrossRef]

16. Aprea, C.; Mastrullo, R.; Renno, C. Determination of the compressor optimal working conditions. Appl. Therm. Eng. 2009, 29, 1991-1997. [CrossRef]

17. Wang, Y.; Jiang, Z.; Zhang, J.; Zhou, C.; Liu, W. Performance analysis and optimization of reciprocating compressor with stepless capacity control system under variable load conditions. Int. J. Refrig. 2018, 94, 174-185. [CrossRef]

18. Bin, T.; Yuanyang, Z.; Liansheng, L.; Guangbin, L.; Le, W.; Qichao, Y.; Haiping, X.; Feng, Z.; Wenhui, M. Thermal performance analysis of reciprocating compressor with stepless capacity control system. Appl. Therm. Eng. 2013, 54, 380-386. [CrossRef]

19. Li, D.; Wu, H.; Gao, J. Experimental study on stepless capacity regulation for reciprocating compressor based on novel rotary control valve. Int. J. Refrig. 2013, 36, 1701-1715. [CrossRef]

20. Liu, G.; Zhao, Y.; Tang, B.; Li, L. Dynamic performance of suction valve in stepless capacity regulation system for large-scale reciprocating compressor. Appl. Therm. Eng. 2016, 96, 167-177. [CrossRef]

21. Porkhial, S.; Khastoo, B.; Modarres Razavi, M.R. Transient characteristic of reciprocating compressors in household refrigerators. Appl. Therm. Eng. 2002, 22, 1391-1402. [CrossRef]

22. Balduzzi, F.; Tanganelli, A.; Ferrara, G.; Babbini, A. Two-dimensional approach for the numerical simulation of large bore reciprocating compressors thermodynamic cycle. Appl. Therm. Eng. 2018, 129, 490-501. [CrossRef]

23. Negrão, C.O.R.; Erthal, R.H.; Andrade, D.E.V.; Silva, L.W.d. A semi-empirical model for the unsteady-state simulation of reciprocating compressors for household refrigeration applications. Appl. Therm. Eng. 2011, 31, 1114-1124. [CrossRef]

24. Diniz, M.C.; Hermes, C.J.L.; Deschamps, C.J. Transient simulation of small-capacity reciprocating compressors in on-off controlled refrigerators. Int. J. Refrig. 2019, 102, 12-21. [CrossRef]

25. Liang, K.; Stone, R.; Hancock, W.; Dadd, M.; Bailey, P. Comparison between a crank-drive reciprocating compressor and a novel oil-free linear compressor. Int. J. Refrig. 2014, 45, 25-34. [CrossRef]

26. Park, M.; Jung, Y.; Lee, J.; Lee, J.; Ahn, Y. Performance Evaluation of a Crank-driven Compressor and Linear Compressor for a Household Refrigerator. J. Korean Soc. Power Syst. Eng. 2017, 21, 5-12. [CrossRef]

27. Hanlon, P.C. Compressor Handbook; McGraw-Hill Education: New York, NY, USA, 2001; ISBN 978-0070260054.

28. Yang, S.; Tao, W. Heat Transfer, 4th ed.; Higher Education Press: Beijing, China, 2018; ISBN 978-7-14-018918-6. (In Chinese)

(C) 2019 by the authors. Licensee MDPI, Basel, Switzerland. This article is an open access article distributed under the terms and conditions of the Creative Commons Attribution (CC BY) license (http://creativecommons.org/licenses/by/4.0/). 